\title{
Environmental physiology of three species of Collembola at Cape Hallett, North Victoria Land, Antarctica
}

\author{
Brent J. Sinclair ${ }^{\mathrm{a}, *}$, John S. Terblanche ${ }^{\mathrm{a}}$, Matthew B. Scott ${ }^{\mathrm{b}}$, Gregory L. Blatch ${ }^{\mathrm{c}}$, \\ C. Jaco Klok ${ }^{\mathrm{a}, 1}$, Steven L. Chown ${ }^{\mathrm{a}, \mathrm{d}}$ \\ ${ }^{a}$ Spatial, Physiological and Conservation Ecology, Department of Botany and Zoology, University of Stellenbosch, South Africa \\ ${ }^{\mathrm{b}}$ Botany Department, University of Otago, New Zealand \\ ${ }^{\mathrm{c}}$ Department of Biochemistry, Microbiology \& Biotechnology, Rhodes University, South Africa \\ ${ }^{\mathrm{d}}$ Centre for Invasion Biology, Department of Botany and Zoology, University of Stellenbosch, South Africa
}

Received 28 July 2005; received in revised form 8 September 2005; accepted 8 September 2005

\begin{abstract}
The environmental physiology of three speciesof Collembola: Cryptopygus cisantarcticus, Isotoma klovstadi (Isotomidae) and Friesea grisea (Neanuridae) was investigated from November 2002 to February 2003 at Cape Hallett, North Victoria Land, Antarctica. All three species were freeze avoiding, and while supercooling points were variable on seasonal and daily scales in I. klovstadi and C. cisantarcticus, they remained largely static in F. grisea. LT50 (temperature where $50 \%$ of animals are killed by cold) was $-13.6,-19.1$ and $-19.8{ }^{\circ} \mathrm{C}$ for C. cisantarcticus, I. klovstadi and F. grisea, respectively. Upper lethal temperature was 34,34 and $38^{\circ} \mathrm{C}$ for $\mathrm{C}$. cisantarcticus, I. klovstadi and $F$. grisea. Critical thermal minimum onset (the temperature where individuals entered chill coma) was ca. $-7,-12$ and $-8{ }^{\circ} \mathrm{C}$ for C. cisantarcticus, I. klovstadi and F. grisea, and $25 \%$ of $I$. klovstadi individuals froze without entering chill coma. Critical thermal maximum (the onset of spasms at high temperature) was 30,33 and $34{ }^{\circ} \mathrm{C}$ for C. cisantarcticus, I. klovstadi and F. grisea. Haemolymph osmolality was approximately $720 \mathrm{mOsm}$ for $C$. cisantarcticus and $680 \mathrm{mOsm}$ for I. klovstadi, and both species showed a moderate degree of thermal hysteresis, which persisted through the season. Desiccation resistance was measured as survival above silica gel, and the species survived in the rank order of $C$. cisantarcticus $<<$. klovstadi $=F$. grisea. Desiccation resulted in an increase in haemolymph osmolality in I. klovstadi, and water was quickly regained by desiccation-stressed individuals that had access to liquid water, but not by individuals placed in high humidity, indicating that this species is unable to absorb atmospheric water vapour. SDS-PAGE did not suggest any strong patterns in protein synthesis either seasonally or in response to temperature or desiccation stress. Microclimate temperatures were measured at sites representative of collection sites for the three species. Microclimate temperatures were highly variable on a diurnal and weekly scale (the latter relating to weather patterns), but showed little overall variation across the summer season. Potentially lethal high and low temperatures were recorded at several sites, and it is suggested that these temperature extremes account for the observed restriction of the less-tolerant C. cisantarcticus at Cape Hallett. Together, these data significantly increase the current knowledge of the environmental physiology of Antarctic Collembola.
\end{abstract}

(C) 2005 Elsevier Ltd. All rights reserved.

Keywords: Cold tolerance; Supercooling point; Critical thermal limits; Desiccation; Osmoregulation; Osmolality; Stress protein; Microclimate

\footnotetext{
${ }^{*}$ Corresponding author. Department of Biological Sciences, University of Nevada, Las Vegas, NV 89154-4004, USA. Tel.: + 17028955917.

E-mail address: celatoblatta@yahoo.co.uk (B.J. Sinclair).

${ }^{1}$ Present Address: School of Life Sciences, Arizona State University, Tempe, AZ, USA.
}

\section{Introduction}

The organisms that live in terrestrial Antarctic habitats must tolerate the temperature extremes, aridity, short growing season and long months of complete darkness that characterise Antarctica (Block, 1994). Given current climate change (IPCC, 2001; Doran et al., 2002; Parmesan 
and Yohe, 2003), understanding the physiological tolerances of Antarctic species, and the extent to which these tolerances may influence community dynamics and determine distribution, is an important aspect of managing and conserving Antarctic biodiversity (Convey et al., 2002, 2003; Peck, 2002; Walther et al., 2002; Peck et al., 2004). In terms of species diversity, distribution and abundance, Collembola (springtails) are one of the dominant members of the terrestrial Antarctic fauna. Endemism in the Antarctic springtail fauna is high, and the group is found in habitats extending almost as far south as ice-free land permits (Wise and Gressitt, 1965; Block, 1994). In consequence, research on the ecology and physiology of Antarctic Collembola has a long history (e.g. Ewing, 1922; Gressitt, 1967; Janetschek, 1967; Tillbrook, 1977; Cannon and Block, 1988; Sinclair and Sjursen, 2001a; Worland and Convey, 2001).

All Antarctic Collembola that have been studied are freeze avoiding, surviving sub-zero temperatures by maintaining their body fluids in a liquid state, and are killed upon freezing at a temperature referred to as the supercooling point (SCP) (Cannon and Block, 1988; Sinclair et al., 2003b). Consequently SCP frequency distributions are a valid and useful way to assess the population distribution of cold tolerance in these species (Cannon and Block, 1988; Worland and Convey, 2001). Bimodal SCP distributions have been commonly described, and seem to be a consequence of ice nucleators from food in the gut (Cannon and Block, 1988). The higher (less cold-hardy) mode of the distribution is thought to be made up largely of active, foraging individuals, while the low (more coldhardy) group are thought to be non-feeding or moulting individuals (Worland, 2005), with a general shift to the low group also observed in preparation for winter (Cannon and Block, 1988). Recently, rapid shifts between these groups in response to diurnal temperature cycles have been demonstrated in species from the maritime (Worland and Convey, 2001) and continental (Sinclair et al., 2003b) Antarctic. However, bimodal SCP distributions are absent in Friesea grisea (Neanuridae) at Cape Hallett (Sinclair et al., 2003b) and possibly also in Gomphiocephalus hodgsoni (Hypogastruridae) at Cape Bird (Sinclair and Sjursen, 2001a), suggesting that bimodality may not be the rule in nonisotomid species. Thermal hysteresis proteins, which stabilise the body fluids of supercooled insects against homogeneous ice nucleation and prevent inoculative freezing (Zachariassen and Husby, 1982; Zachariassen and Kristiansen, 2000) are present in several alpine Collembola (Zettel, 1984) and have been detected in G. hodgsoni (Sinclair and Sjursen, 2001a), but are not present in Cryptopygus antarcticus (Isotomidae) from the maritime Antarctic (Block and Duman, 1989).

Apart from cold tolerance, other aspects of the thermal biology of Antarctic Collembola have received less attention. As may be expected, Antarctic Collembola are able to maintain activity at low temperatures, with reported chill coma temperatures $(\approx$ critical thermal minimum) ranging from near zero in G. hodgsoni (Janetschek, 1967) to $-10^{\circ} \mathrm{C}$ in C. antarcticus (Sømme and Block, 1982). Thermal preferenda are often surprisingly high: in the region of $10^{\circ} \mathrm{C}$ for $\mathrm{G}$. hodgsoni (Fitzsimons, 1971) and $9-13^{\circ} \mathrm{C}$ for warm-acclimated C. antarcticus (Hayward et al., 2003). Upper thermal limits have rarely been measured, although Fitzsimons (1971) reported an upper lethal temperature of $+29.5^{\circ} \mathrm{C}$ for $\mathrm{G}$. hodgsoni. With the exceptions of an investigation of the potential of Hsp70 as an ecotoxicological biomarker (Staempfli et al., 2002) and the demonstration of the induction of Hsp70 in response to desiccation (Bayley et al., 2001), molecular responses to thermal or other environmental stresses (see Chown and Nicolson, 2004, for review) have not been investigated in Collembola.

Low precipitation, sub-zero temperatures, and high water vapour deficit mean that desiccation is a major stress for terrestrial Antarctic organisms (Kennedy, 1993). Cutaneous respiration, permeable cuticles and a large surface area:volume ratio conspire to make Collembola susceptible to desiccation (Hopkin, 1997), and significant interspecific variation in behaviour, cuticle structure and consequently rate of water loss mean that there is significant among-species variation in desiccation tolerance (Hopkin, 1997; Hertzberg and Leinaas, 1998). Hayward et al. (2004) suggested that the fine-scale distributions of Friesea grisea and $C$. antarcticus at Rothera on the Antarctic Peninsula may be a consequence of their different rates of or tolerances to water loss. Collembola are generally poor osmoregulators (Hopkin, 1997). Haemolymph osmolalities of most Collembola under normal conditions fall between 200 and $400 \mathrm{mOsm} \mathrm{kg}^{-1}$ (Hopkin, 1997; Sinclair and Chown, 2002). Early spring haemolymph osmolalities of up to $1755 \mathrm{mOsm} \mathrm{kg}^{-1}$, decreasing to ca. $500 \mathrm{mOsm} \mathrm{kg}^{-1}$ in summer, were reported in G. hodgsoni (Sinclair and Sjursen, 2001a). Block and Harrisson (1995) report much lower osmolalities of ca. $284 \mathrm{mOsm} \mathrm{kg}^{-1}$ for C. antarcticus.

An essential element of environmental physiology is determination of the conditions that organisms actually encounter (Bale, 1987; Kingsolver, 1989; Danks, 1991; Sinclair et al., 2003c). In terrestrial Antarctic habitats, microclimatic temperatures have long been collected as part of ecological and physiological studies (e.g. Pryor, 1962; Janetschek, 1963, 1967; Rudolph, 1963), and this practice has been significantly advanced by the development and availability of automatic dataloggers (e.g. Block, 1985; Sømme, 1986; Friedmann et al., 1987; Davey et al., 1992; Sinclair and Sjursen, 2001a). Although most records are limited to temperature data, these are of value in assessing the magnitude and frequency of thermal stresses in the field. Indeed, recent assessments of daily temperature variation prompted greater temporal resolution of cold hardiness studies, revealing diurnal changes in the SCPs of arthropods in response to this variation (Worland and Convey, 2001; Sinclair et al., 2003b). Integrating microclimate temperature recordings and physiological information is therefore essential for understanding the likelihood 
that organisms experience physiologically stressful conditions in the field, the variability of these stresses at small and large spatial scales, and their importance in influencing population dynamics and consequently the abundance and distribution of the species concerned. The extent to which organisms are operating at the edge of their physiological tolerances is of great significance for understanding the changes that are likely to be induced by rapid climatic change (Holt et al., 1997; Kingsolver and Huey, 1998; Sinclair, 2001a).

Although apparently extensive, as the brief review above suggests, physiological and ecological investigations of Antarctic Collembola have been dominated by research on C. antarcticus in the Maritime Antarctic, and this work has contributed substantially to modern understanding of springtail biology in the Antarctic. However, comprehensive investigations of the biology of one species in a single region is inadequate for understanding the environmental physiology of a higher taxon, and its likely responses to climate change (Chown et al., 2002a). This is especially true for the wide range of species found across Antarctica: a continent whose regions' climates vary dramatically, both currently and in predicted responses to global climate change (Convey, 2001; Doran et al., 2002; Walther et al., 2002). Here, we therefore extend previous studies of the environmental physiology of the Antarctic springtail fauna by investigating the thermal biology and water relations of three species of Collembola at Cape Hallett, North Victoria Land; an area for which little information is currently available. Furthermore, we investigate protein expression in one of the species, and present high-resolution microclimate temperature data for a summer at Cape Hallett, placing the physiological measurements in an appropriate environmental context.

\section{Methods}

\subsection{Study site and animals}

This work was conducted at the 72 ha Cape Hallett icefree area $\left(72^{\circ} 19^{\prime} \mathrm{S}, 170^{\circ} 13^{\prime} \mathrm{E}\right.$; Antarctic Specially Protected Area No. 106, http://www.cep.aq/apa/) in North Victoria Land, Antarctica. The site consists of basalt screes, moraines and beach deposits (Harrington et al., 1967). Approximately half of the area is occupied by an Adelie Penguin (Pygoscelis adeliae) colony, and is consequently devoid of terrestrial arthropods (Sinclair, Scott, Klok, Terblanche, Marshall, Reyers and Chown, in preparation). The rest of the habitat may be divided into 'algal flats' (low-lying undulating moraine with abandoned penguin mounds, moss and algal communities and often abundant flowing or standing surface water, sometimes several centimetres deep during the height of snowmelt); 'scree slope', a steep, unstable area $20-250 \mathrm{~m}$ a.s.l. which is dominated by lichen communities, with scattered algae and mosses; and 'ridge' habitat, above snowfields at approximately $300 \mathrm{~m}$ a.s.l., an exposed habitat with a distinct community of lichens. Data presented here are from animals sampled from the algal flats and lower scree slope habitats. The position of the scree slope, and the Hallett Peninsula which rises to $1770 \mathrm{~m}$ behind it, result in a diurnal sun-shade cycle during the summer with consequent large daily temperature variations (Sinclair et al., 2003b).

Three species of Collembola occur at Cape Hallett (Wise and Shoup, 1967). Friesea grisea (Schäffer) (Neanuridae) is sparsely distributed throughout the entire area, with foci at the edges of moss banks. Cryptopygus cisantarcticus Wise (Isotomidae) is found largely in the moist algal flats; and Isotoma klovstadi Carpenter (Isotomidae) is extremely abundant in vegetated areas of the scree slope (Pryor, 1962; Wise and Shoup, 1967; Sinclair et al., 2003b). All three species are also present in soil at the ridge site (Sinclair et al., in preparation).

Collembola were collected from beneath rocks using aspirators, and placed in dry plastic containers (for immediate use, e.g. SCP determinations) or onto moist Plaster-of-Paris, if they were to be stored for more than a few minutes. During daytime in mid-summer, I. klovstadi could be found in large aggregations grazing on the surface of moss. These 'foraging' individuals were collected from the moss surface with an aspirator for some SCP experiments. Field-fresh animals were always kept in the shade on snow at the camp $\left(\mathrm{ca} .0^{\circ} \mathrm{C}\right)$, and used within $1 \mathrm{~h}$ of collection. Springtails for acclimation (generally I. klovstadi) were placed in plastic vials with a piece of moist filter paper and a mesh-covered perforated lid, which was placed within a larger sealed container containing 25-40 ml distilled water, maintaining $100 \%$ relative humidity $(\mathrm{RH})$. Acclimation to $5^{\circ} \mathrm{C}$ in $24 \mathrm{~h}$ light was carried out as described by Sinclair et al. (2003b) in a Sable Systems PTC1 Peltier-effect Temperature Cabinet (Sable Systems Inc., Henderson, Nevada, USA) with white light provided by a Black Diamond Ion LED lamp (Black Diamond Equipment, Salt Lake City, UT, USA).

With the exception of protein electrophoresis, all of the data were gathered on site from a tent-based field laboratory at Cape Hallett between 9 November 2002 and 27 January 2003. Generators typically operated for $14 \mathrm{~h}$ per day and could not be operated during blizzards (ca. 10/77 days), limiting the practicability of extended acclimation treatments.

\subsection{Supercooling points}

SCPs, (see Block and Young, 1979, for a general description) were measured in freshly caught Collembola within a few minutes of their return to the laboratory. Two or three springtails were affixed with silicone grease to the tip of a 40-gauge Type $\mathrm{T}$ thermocouple connected to an eight channel Grant Squirrel SQ800 data logger (Grant Instruments, Cambridge, UK). Temperature measurements were made continuously and averaged over $4 \mathrm{~s}$ intervals. The thermocouples and springtails were placed in $1.5 \mathrm{ml}$ 
microcentrifuge tubes in an aluminium block cooled by a Peltier module as described by Sinclair et al. (2003b). Springtails were cooled at $0.5^{\circ} \mathrm{C} \mathrm{min}^{-1}$ from 0 to $-40{ }^{\circ} \mathrm{C}$ (preliminary experiments indicated that SCP was not affected by varying the cooling rate between 0.8 and $0.05^{\circ} \mathrm{C} \mathrm{min}^{-1}$ ), and SCPs were derived from the latent heat of crystallisation (Block and Young, 1979), which was clearly discernible for each individual attached to the thermocouple. No pre-freeze mortality or survival of freezing was observed in preliminary observational experiments, where groups of springtails individually placed on thermocouples were cooled until half the individuals had frozen, and movement observed in unfrozen individuals upon rewarming (B.J. Sinclair, unpublished observations). Thus, it is assumed that, as for other Antarctic Collembola (Cannon and Block, 1988; Sinclair and Sjursen, 2001a), the SCP is a valid measure of the acute lower lethal temperature in the species at Cape Hallett.

SCPs (usually of 20-30 individuals) were measured at regular intervals throughout the season, from late-November to mid-January for a total of five measurements for each species. Because substantial diurnal variation in SCP was found in I. klovstadi and C. cisantarcticus (Sinclair et al., 2003b), SCPs of all three species were measured during the 'day' (when the study site was in the sun, between 11:00 and 16:30 h) and 'night' (when the study site was in the shade, between 23:30 and $04: 30 \mathrm{~h}$ ) on two consecutive nights and days (unless interrupted by poor weather), and the data from the 2 days or nights pooled for each sampling point. Although the December data reported here were used by Sinclair et al. (2003b) to characterise the diurnal changes in SCP, this is the first presentation of the full seasonal spectrum of the SCP data.

SCPs of F. grisea were unimodal, but strongly skewed (Sinclair et al., 2003b), so the absolute SCPs during night and day were compared between sampling periods using Generalized Linear Models (GLZ, Poisson distribution and identity link) in Statistica (v. 6.1, Statsoft, Tulsa, Oklahoma, USA). SCP distributions of I. klovstadi and C. cisantarcticus were approximately bimodal, and were split into high and low groups (HG and LG, respectively), with cut-offs of $-16^{\circ} \mathrm{C}$ for C. cisantarcticus and $-18^{\circ} \mathrm{C}$ for I. klovstadi (see Sinclair et al., 2003b, and references therein for rationale). The distributions of high and low groups of SCPs were approximately normal, and the means of the high and low groups were compared among and within sampling dates using ANOVA on Statistica. Counts of individuals in high and low groups were compared using GLZ (Poisson distribution and identity-link) in Statistica. Daytime SCP distributions of foraging and non-foraging individuals of I. klovstadi were combined for this comparison.

\subsection{Upper and lower lethal temperatures}

Upper and lower lethal temperatures (ULT and LLT, respectively) for each species were determined on field-fresh animals in mid-December 2002 using a cumulative technique modified from that of Worland et al. (1992). Collembola were placed in $1.5 \mathrm{ml}$ microcentrifuge tubes in groups of 10 individuals (with moist filter paper to prevent desiccation for ULT determinations), and placed in a plastic bag in a Grant LTD-20 water bath controlled by a PZ-1 programmer (Grant Instruments, Cambridge, UK) for equilibration for $15 \mathrm{~min}$ at $5{ }^{\circ} \mathrm{C}$. For ULTs, the temperature of the bath was then increased at $0.1{ }^{\circ} \mathrm{C}$ min $^{-1}$ to a set high temperature, where the temperature was held for $1 \mathrm{~h}$, after which 3 tubes for each species were removed to tent temperature (ca. $10-15^{\circ} \mathrm{C}$ ) and then $5^{\circ} \mathrm{C}$ for recovery. The temperature was then increased at $0.1{ }^{\circ} \mathrm{C} \mathrm{min}{ }^{-1}$ with one hour hold periods and 3 tubes were removed for each species at $1{ }^{\circ} \mathrm{C}$ increments. After preliminary experiments to determine a suitable range of temperatures, tubes were removed at temperatures from 28 to $35^{\circ} \mathrm{C}$ for $C$. cisantarcticus ( $n=8$ temperatures), from 31 to $37^{\circ} \mathrm{C}$ for $I$. klovstadi ( $n=7$ temperatures), and from 31 to $39^{\circ} \mathrm{C}$ for $F$. grisea ( $n=9$ temperatures). A similar protocol was followed for LLTs, with cooling rates of $0.1^{\circ} \mathrm{C} \mathrm{min}{ }^{-1}$, and 3 tubes of each species were removed at -8 and $-10{ }^{\circ} \mathrm{C}$, and thereafter at 5 degree intervals to $-30^{\circ} \mathrm{C}$ ( $n=6$ temperatures). Tubes were removed to $5^{\circ} \mathrm{C}$ for recovery. Logistic regression models of survival (see Quinn and Keogh, 2002) of the form:

$p($ alive $)=1-\frac{\mathrm{e}^{a+b x}}{1+\mathrm{e}^{a+b x}}$

were fitted to the ULT and LLT data using the nonlinear estimation module of Statistica, and standard errors were calculated from error estimates on the slope and intercept of the fitted equation. ULT50 and LLT50 (the high and low temperatures, respectively, where $50 \%$ mortality is expected) were estimated from the fitted equation.

\subsection{Critical thermal minimum and maximum}

Critical thermal minima (CTmin) and critical thermal maxima (CTmax) were determined on four occasions across the summer. Field-fresh springtails were contained in $5 \mathrm{~mm}$ diameter circular plastic enclosures on a cold stage cooled by a Grant LTD20 water bath and PZ1 controller, and observed with a dissecting microscope. Each species was assessed separately, and all measurements were made by the same observer (CJK). Fifteen field-fresh animals were placed individually in the enclosures and allowed to equilibrate at $0{ }^{\circ} \mathrm{C}$ for $15 \mathrm{~min}$ (escapees were excluded from observation, reducing sample size in some instances). The stage was then cooled at $0.25^{\circ} \mathrm{C} \mathrm{min}^{-1}$ to $1^{\circ} \mathrm{C}$ below the lowest $\mathrm{CTmin}$ onset, where they were held for $5 \mathrm{~min}$ before rewarming. CTmi$\mathrm{n}_{\text {onset }}$ was defined during cooling as the temperature at which animals could not maintain coordinated movement even when agitated by vigorously tapping the base of the cold stage. During rewarming the CTmin $\mathrm{Crecovy}_{\text {was defined }}$ as the resumption of coordinated movement including righting and walking - mere movement of legs and antennae 
was discounted. CTmax was determined in a similar fashion for the same individuals with a warming rate of $0.25^{\circ} \mathrm{C} \mathrm{min}^{-1}$, and was defined as the onset of muscular spasms following the vigorous activity of the animals at high temperatures (Lutterschmidt and Hutchison, 1997). Freezing was observed as a violent stiffening of the body accompanied by extension of the furca and legs in some individuals, and if more than $50 \%$ of the individuals froze during a CTmin run, the frozen individuals were removed, and new individuals introduced to the chamber for CTmax determination. Critical thermal limits were compared between species and across the season using ANOVA in Statistica, followed by Tukey's HSD post hoc comparison. The within-species relationship between $\mathrm{CTmin}_{\text {onset, }}$

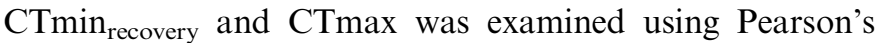
correlation coefficient on data for all individuals (regardless of sampling date) for which data from the three parameters was available ( $n=34,57$ and 54 for $I$. klovstadi, F. grisea and C. cisantarcticus, respectively).

\subsection{Haemolymph osmolality}

Haemolymph osmolality was determined optically using a calibrated Clifton Nanoliter Osmometer (Clifton Technical Physics, NJ, USA), using standard methods (Sjursen and Sømme, 2000). Haemolymph was obtained from the drop exuded after the amputation of a leg or antenna of an animal held under liquid paraffin to prevent evaporation. Individual samples of haemolymph from I. klovstadi were used, whereas samples pooled from the haemolymph of 3-4 individuals were used for $C$. cisantarcticus. Haemolymph from $F$. grisea rapidly coagulated and oxidation turned the fluid opaque, and an approximate determination of osmolality was made on only one occasion for this species. Haemolymph osmolality was determined on six occasions between late-November 2002 and mid-January 2003 for I. klovstadi and C. cisantarcticus $(n=10$ replicates per determination, apart from the initial sample, when $n=25$ for I. klovstadi and $n=15$ for C. cisantarcticus). Haemolymph was also examined for thermal hysteresis activity, indicated by a discrepancy between the melting and freezing points of a single ice crystal. Hysteresis in mOsm $\mathrm{kg}^{-1}$ was converted into ${ }^{\circ} \mathrm{C}\left(1000 \mathrm{mOsm}=1.86^{\circ} \mathrm{C}\right)$, on occasions where it was found. Haemolymph osmolality and thermal hysteresis activity were compared across the season using ANOVA.

\subsection{Desiccation resistance}

Desiccation resistance was compared between species using a modification of the method of Hertzberg and Leinaas (1998). All experiments were conducted from 29 November to 1 December 2002. Collembola were acclimated for 3 days at $5{ }^{\circ} \mathrm{C}$ in $100 \%$ RH with moist filter paper before being placed individually into $1.5 \mathrm{ml}$ microcentrifuge tubes $(n=20$ individuals per species) with a large crystal of dry silica gel attached to the interior of the lid (treatment - approximately 5\% RH) or a piece of moist filter paper (control-approximately 100\% RH). The tubes were then placed in a sealed plastic bag in a Grant LTD20 water bath (Grant Instruments, Cambridge UK) at $20^{\circ} \mathrm{C}$. After 30 (C. cisantarcticus) or $60 \mathrm{~min}$ had elapsed, the tubes were removed every 30 (I. klovstadi) or 15 (F. grisea and $C$. cisantarcticus) minutes, and survival (coordinated movement) of each individual scored. Once a treatment individual had been classified as dead, it was removed and placed in $100 \% \mathrm{RH}$ at $5{ }^{\circ} \mathrm{C}$ to look for recovery after $24 \mathrm{~h}$. A logistic regression model of survival was fitted as for ULT and LLT data, and the time to $50 \%$ mortality (analogous to the LLT50 or ULT50) and standard errors estimated.

\subsection{Osmoregulation in Isotoma klovstadi}

We examined the recovery from desiccation of $I$. klovstadi. Isotoma klovstadi was acclimated in groups of 100 at $5{ }^{\circ} \mathrm{C}$ at $100 \% \mathrm{RH}$ for 3 days, before being exposed en masse to silica gel at $5{ }^{\circ} \mathrm{C}$ for $3 \mathrm{~h}$. Collembola (in containers) were then removed from silica gel, and either supplied with moist filter paper in $100 \% \mathrm{RH}$ ('Free Water' treatment), or placed in $100 \% \mathrm{RH}$ without direct access to water ('Water Vapour' treatment). Measurements of SCPs $(n \approx 16$ individuals), haemolymph osmolality ( $n=5$ individuals) and gravimetric water content were made before desiccation, at the conclusion of the $3 \mathrm{~h}$ desiccation, and at 1, 3, 6, 12 and $24 \mathrm{~h}$ after the conclusion of desiccation (Free Water), and at 4 and $26 \mathrm{~h}$ after conclusion of desiccation (Water Vapour). Gravimetric water content was measured for 3 groups of 25-30 springtails per treatment as described by Sinclair et al. (2003b). Comparisons were made between groups using ANOVA (osmolality), Kruskal-Wallis Rank ANOVA (SCP medians) and analysis of covariance (ANCOVA) with dry mass as the covariate (water content).

\subsection{Total protein analysis}

I. klovstadi, the largest and most abundant springtail at the site, was selected for qualitative protein analysis by sodium dodecyl suphate (SDS)-polyacrylamide gel electrophoresis (SDS-PAGE, Laemmli, 1970) on field-fresh individuals on six occasions throughout the summer. I. klovstadi for electrophoresis were also acquired from experiments investigating response to and recovery from desiccation (see below), and rapid cold-hardening (based on the procedures of Nunamaker (1993), see Sinclair et al. (2003b) for full rationale and methodology). Briefly, groups of field-fresh I. klovstadi were exposed in groups of 20 individuals to $2 \mathrm{~h}$ treatments in $1.5 \mathrm{ml}$ tubes as controls $\left(5^{\circ} \mathrm{C}, 100 \% \mathrm{RH}\right)$, or at 28 (with moist filter paper), $0,-5$ or $-9^{\circ} \mathrm{C}$ (all in dry tubes); as well as $-5^{\circ} \mathrm{C}$ followed by a $2 \mathrm{~h}$ recovery period at $+5^{\circ} \mathrm{C}\left({ }^{\circ}-5\right.$ gap'), three hours in a container with low relative humidity provided by silica gel ('desiccation') and a slow cooling treatment ( +5 to $-2{ }^{\circ} \mathrm{C}$ at $\left.1^{\circ} \mathrm{Ch}^{-1}\right)$. 
Approximately $5 \mathrm{mg}$ of field-fresh or acclimated and treated I. klovstadi were weighed to $\pm 1 \mu \mathrm{g}$ and immediately homogenised in $50 \mu 1$ SDS-PAGE sample-treatment buffer (2\% SDS, $10 \%$ glycerol, $100 \mathrm{mM}$ Dithiothreitol (DTT), $60 \mathrm{mM}$ Tris $[\mathrm{pH} 6.8]$ and $0.001 \%$ bromophenol blue (Laemmli, 1970), and stored at sub-zero temperatures (below $-5{ }^{\circ} \mathrm{C}$ in the field for up to 2 months, below $-20{ }^{\circ} \mathrm{C}$ for transport from Antarctica to New Zealand (1 week), and thereafter below $-50{ }^{\circ} \mathrm{C}$ until processing). In the laboratory in South Africa, samples were boiled for $5 \mathrm{~min}$ and diluted with SDS-PAGE loading buffer $(100 \mathrm{mM}$ Tris (pH 6.8), 5\% $\beta$-mercaptoethanol, $4 \%$ SDS, $0.2 \%$ Bromophenol Blue, $20 \%$ Glycerol) to a final amount of $0.35 \mathrm{mg}$ fresh mass/lane. Proteins were separated by SDS-PAGE using the BioRad Mini-PROTEAN II System (BioRad, Hercules, CA, USA) and a 10\% polyacrylamide resolving gel. The size of protein bands was estimated with reference to standard molecular mass markers (Broad Range SDSPAGE markers, BioRad). Western analysis was performed according to Towbin et al. (1979). The enhanced chemiluminescence system (ECL; Amersham) was used to detect heat shock proteins during Western analysis using mouse anti-Hsp70 and mouse anti-Hsp90 antibodies.

\subsection{Microclimate recordings}

\subsubsection{Measurement of microclimate data}

Microclimate temperatures were measured every $10 \mathrm{~min}$ throughout the summer beneath rocks representative of those turned to collect each species. I. klovstadi habitat was monitored at two different sites (ca. $120 \mathrm{~m}$ apart) at the same elevation. Temperature at the first site was monitored by two channels of a Hobo H-8 logger with TMCX-HA thermistor probes (Onset Computer Corporation, Pocasset, MAs, USA) under two stones (184 and $107 \mathrm{~cm}^{2}, 22$ and $64 \mathrm{~mm}$ thick, respectively). Temperatures at site 1 were monitored from 16 November 2002-5 January 2003, before the receding snowbank made access to the logger across the unstable scree slope overly destructive to the habitat. The second I. klovstadi site consisted of three stones, of $26-151 \mathrm{~cm}^{2}$ and between 12 and $74 \mathrm{~mm}$ thick. Temperatures were logged by calibrated iButton Thermochron data loggers (accurate to $\pm 0.5^{\circ} \mathrm{C}$, Dallas Semiconductors, Dallas, TX, USA) or probes from a Hobo H-8 logger as above. At the two I. klovstadi sites, stone surface temperatures were also monitored with an unshielded TMx-HA thermistor probe at each site.

C. cisantarcticus stones were located in a moist area of the algal flat, near the southern edge of the penguin colony, whereas the $F$. grisea stones were in a drier area, close to I. Klovstadi site 2 (see Sinclair et al., 2003b, for a description of these stones) Temperatures at $F$. grisea and C. cisantarcticus sites were monitored with calibrated iButtons as above. The two most distant sites (I. klovstadi site 1 and C. cisantarcticus) were approximately $400 \mathrm{~m}$ apart.

\subsubsection{Analysis of microclimate data}

Summary statistics for each data logger location were calculated using Microsoft Excel. Microclimate data were also analysed with VisualBasic macros in Microsoft Excel (Microsoft, Seattle, WA, USA), using the general approach described by Sinclair (2001a,b). A current version of the macros (v. 2.0.2) is available upon request from B.J. Sinclair (celatoblatta@yahoo.co.uk).Three basic types of summaries were extracted from the data: cooling rates across a specific threshold (calculated in all cases for the 60 min preceding the threshold); the number of cycles that cross a threshold; the period of time (in minutes) spent above or below a threshold. All cooling rates calculated by the macro were checked manually, and only those calculated for a period of monotonically decreasing temperature were used in analyses.

General biological thresholds were analysed across the entire dataset for each logger, but comparisons between loggers and habitats were made only for the month of December 2002, for which a complete dataset was available for all 11 logger sites. Biologically relevant thresholds were derived from the physiological data described elsewhere in the paper. ULT5 and ULT50 (upper temperatures at which $5 \%$ and $50 \%$ of individuals are expected to die) were calculated using the logistic regression equations for the upper thermal limit data, while SCP5 and SCP50 (temperatures at which 5 and $50 \%$ of individuals are expected to freeze upon acute exposure) were derived from cumulative SCP distributions of the entire SCP data set for each species. To determine the likelihood of potentially lethal thermal events during the summer, the number of times in each complete dataset that the temperature dropped below $0{ }^{\circ} \mathrm{C}$ (freeze-thaw cycles); the number of times it dropped below the SCP5 and SCP50 for each species of springtail and the number of times the temperature increased above the ULT5 and ULT50 for each species were counted. The cooling rate for the hour preceding the crossing of a threshold, with thresholds of $+10,+5,0,-5$ and $-10^{\circ} \mathrm{C}$, was also calculated to make comparisons of cooling rates across the temperature spectrum. Cooling rates at $0{ }^{\circ} \mathrm{C}$ were compared between habitats using a generalized linear model (Gamma distribution, Identity-link; Statistica). Counts of freeze-thaw cycles across $0{ }^{\circ} \mathrm{C}$ and $-3.2{ }^{\circ} \mathrm{C}$, as well as the total time spent above 0 and $+10^{\circ} \mathrm{C}$ were compared between habitats using a Kruskal-Wallis rank ANOVA followed by non-parametric multiple comparisons in Statistica. A correlation matrix of area and volume of stones (area was calculated using the method of Sinclair et al., 2001) with the above thresholds was constructed, and the relationship between stone size and microclimate thermal characteristics tested using Spearman's rank correlation in Statistica.

\subsection{Relationships between physiological and climatic variables}

The effects of prevailing microclimate temperature conditions on physiological variables measured on field 
fresh animals were examined using Pearson's correlation coefficients. Central measures of cold tolerance (mean day and night $\mathrm{HG}$ and LG SCP for I. klovstadi and $C$. cisantarcticus, and median SCP for $F$. grisea); maximum and minimum SCP, mean $\mathrm{CTmin}_{\text {onset }}$, CTmin recovery $_{\text {and }}$ CTmax; and mean haemolymph osmolality were used. Microclimate temperature variables were calculated from data logger data from the representative sites for that species (see above). Means of microclimate variables were calculated as the mean of the means recorded from the three loggers at a site, whereas the maximum or minimum was the absolute maximum or minimum across all three loggers at the site. Mean, maximum, minimum and range ( $\max -\min )$ temperatures were calculated for 1, 3 and 5 days preceding the measurement of the physiological variable and used for the correlation analysis. Significance of all multiple comparisons was corrected using a table-wide step-up false discovery rate correction (García, 2004).

\section{Results}

\subsection{Supercooling points}

SCPs were unimodal (but strongly skewed, skewness $\pm \mathrm{SEM}=1.56 \pm 0.16$ ) in $F$. grisea, and bimodal in I. klovstadi and C. cisantarcticus (Fig. 1). SCPs of $F$. grisea did not change significantly across the season, nor between 'day' and 'night' (Table 1; see also Sinclair et al., 2003b). High- and low-group SCPs of $C$. cisantarcticus also did not change between night and day (Table 1). In one period (26 Nov-2 Dec 2002, which also had the lowest mean temperature), I. klovstadi low group mean was significantly lower during the night than during the day (which accounts for the apparent third mode in the overall SCP distribution, Fig. 1), but in all other cases the means did not differ between day and night (Table 1). The HG:LG ratio of both I. klovstadi and C. cisantarcticus differed substantially between day and night (Day/nightHigh/Low interaction: I. klovstadi: Wald $\chi^{2}=7.37, p=$ $0.007, \mathrm{df}=1 ;$ C. cisantarcticus: Wald $\chi^{2}=8.43, p=0.004$, $\mathrm{df}=1$ ), with a strong night-time bias towards LG (see also Sinclair et al., 2003b. From November to January, the proportion of $\mathrm{HG} C$. cisantarcticus during the day increased markedly (Table 1). A similar pattern was observed for I. klovstadi if foraging animals were pooled in the daytime sample, with a larger proportion of $\mathrm{HG}$ animals in December and January than in November (Table 1). SCP parameters of each species of springtail were not significantly correlated with any of the environmental temperature indices measured (Pearson's correlation coefficient, $p>0.05$ in all cases).

\subsection{Upper and lower lethal temperatures}

The highest temperatures survived were 34,34 and $38^{\circ} \mathrm{C}$ for I. klovstadi, C. cisantarcticus and F. grisea, respectively. Upper lethal temperatures and fitted logistic regression
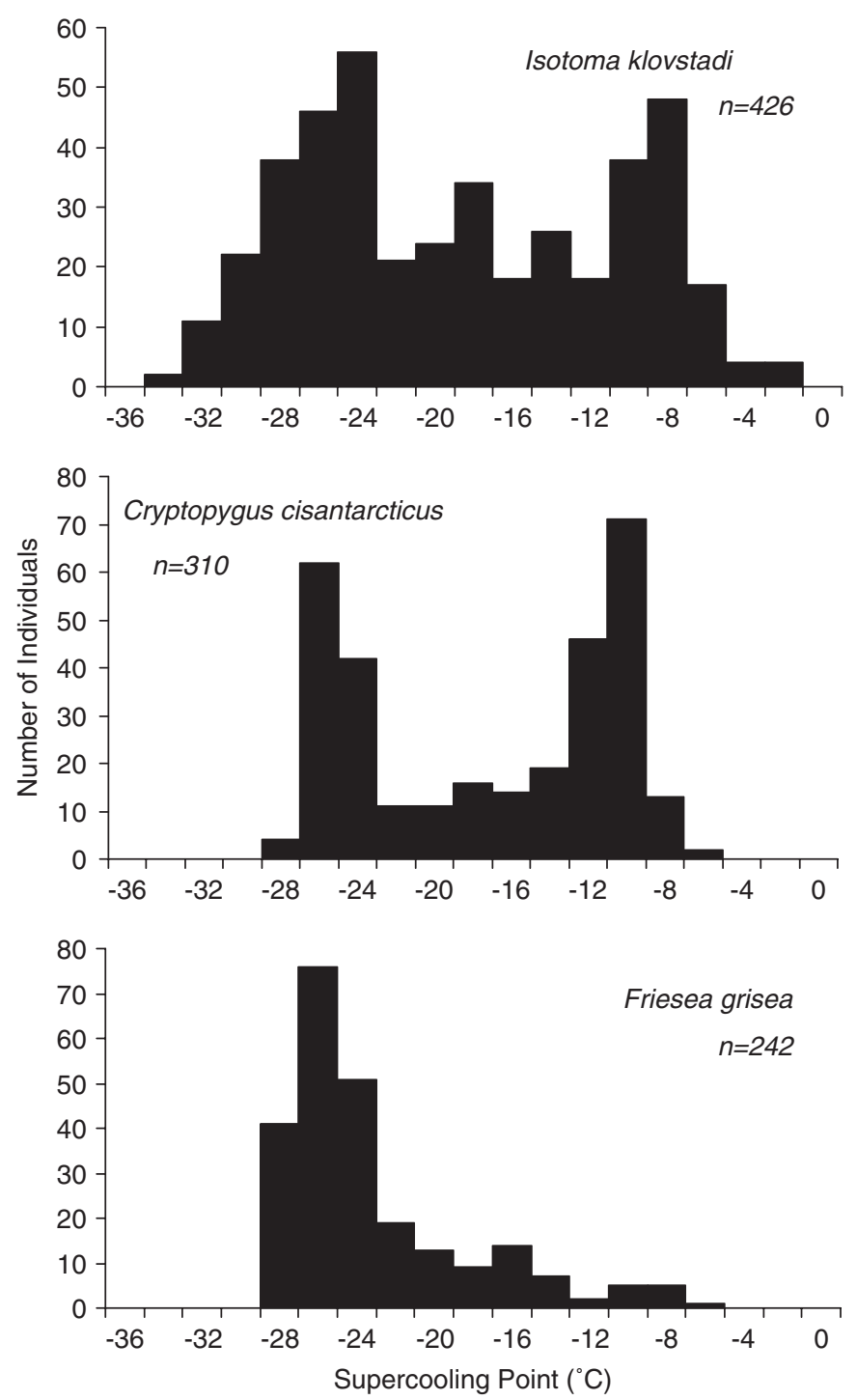

Fig. 1. Combined supercooling point distributions for three species of Collembola at Cape Hallett, Antarctica.

models for all three species are shown in Fig. 2a. The standard errors from the model suggest no significant differences between the ULT50s of the three species. However, I. klovstadi has a very rapid, steep response to high temperatures, whereas there is a greater intraspecific variability in the other species, resulting in shallower fitted curves (Fig. 2a). This means that although the maximum temperature survived for I. klovstadi and C. cisantarcticus is identical, high temperature mortality begins at $29^{\circ} \mathrm{C}$ in C. cisantarcticus, but at $33{ }^{\circ} \mathrm{C}$ in I. klovstadi. The rank order of the ULT50 is C. cisantarcticus $<I$. klovstadi $<F$. grisea.

C. cisantarcticus was less cold tolerant than the other species (LLT50s were $-13.6,-19.1$ and $-19.8^{\circ} \mathrm{C}$ for C. cisantarcticus, I. klovstadi and F. grisea respectively, Fig. 2b). As may be expected from the SCPs, the LLT and LLT50 of $I$. klovstadi and $F$. grisea were similar, thus indicating that the rank order of the three species in terms 
Table 1

Summary of supercooling point distributions and means for three species of Collembola at Cape Hallett, Antarctica, during the $2002 / 2003$ summer. Low group included those individuals with $\mathrm{SCP}<-18^{\circ} \mathrm{C}$ (Isotoma klovstadi) or $<-16^{\circ} \mathrm{C}$ (Cryptopygus cisantarcticus). Friesea grisea did not display a bimodal SCP distribution, so median and quartiles are shown. Within species, means with different letters differ significantly (ANOVA: Tukey's HSD $p<0.05 ; I$. klovstadi: Date $\times$ high/low interaction $F_{4,407}=10.05, p<0.001$, Date $\times$ Day/night interaction $F_{4,407}=3.93, p=0.011 ; C$. cisantarcticus: Date $\times$ Day/Night interaction $F_{4,291}=3.05, p=0.018$; GLZ: F. grisea: Between Dates: Wald $\chi^{2}=3.985, p=0.41$, df $=4$; Between day and night: Wald $\chi^{2}=8.040$, $p=0.09, \mathrm{df}=4)$

\begin{tabular}{|c|c|c|c|c|c|}
\hline $\begin{array}{l}\text { Time of day } \\
(n)\end{array}$ & $\begin{array}{l}\text { HG:LG } \\
\text { ratio }\end{array}$ & $\operatorname{Min}\left({ }^{\circ} \mathrm{C}\right)$ & $\operatorname{Max}\left({ }^{\circ} \mathrm{C}\right)$ & $\begin{array}{l}\mathrm{HG} \\
\text { mean } \pm \mathrm{SEM} \\
\left({ }^{\circ} \mathrm{C}\right)\end{array}$ & $\begin{array}{l}\text { LG } \\
\text { mean } \pm \text { SEM } \\
\left({ }^{\circ} \mathrm{C}\right)\end{array}$ \\
\hline
\end{tabular}

\section{Isotoma klovstadi}

13-17 November 2002

26 November-2

December 2002

12-13 December 2002

21-24 December 2002

14-15 January 2003

Cryptopygus

cisantarcticus

26-29 November 2002

2-3 December 2002

12-13 December 2002

21-24 December 2002

14-15 January 2003

Friesea grisea

2-3 December 2002

5-7 December 2002

12-13 December 2002

21-23 December 2002

14 January 2003

\section{Night (9) \\ Day (31)}

Night (52)

Day (65)

Night (31)

Day (36)

Night (41)

Day (43)

Foraging

(20)

Night (33)
Day (38)
Foraging

(28)

(28)

Night (42)
Day (40)

$1: 1.6$

$1: 1.7$

Night (17)

Day (13)

$1.1: 1$

$1: 1.2$

Night (29)

Day (33)

$1: 2.2$

$1.8: 1$

Night (39)

Day (37)

Night (33)

Day (28)

$1.1: 1$

$1.8: 1$

$1: 1.8$

$4.6: 1$

Night (16)

Day (24)

Night (10)

Day (14)

Night (36)

Day (31)

Night (40)

Day (30)

Night (22)

Day (20)
$-27.4$

$-27.2$

-34.4
-32.2
-33.6
-31.8
-24.0
-19.2
-30.0
-30.2
-12.4

-30.8
-31.4
-11.2

$-11.2$

$-27.4$

$-27.0$

$-27.4$

$-27.8$

$-28.0$

$-28.6$

$-28.6$

$-23.4$

$-28.6$

$-29.2$

$-25.0$

$-29.4$

$-29.6$

$-29.8$

$-28.0$

$-28.2$

$-27.6$

$-29.0$

$$
\begin{array}{r}
-9.4 \\
-14.2 \\
-14.2 \\
-6.8 \\
-7.8 \\
-3.6 \\
-8.0 \\
-10.0 \\
-6.4
\end{array}
$$

$-8.6$

$-8.6$

$-3.2$

$$
\begin{array}{ll}
-11.8 \pm 1.2^{\mathrm{wx}} & -30.4 \pm 2.0^{\mathrm{a}} \\
-15.6 \pm 0.4^{\mathrm{w}} & -27.9 \pm 0.7^{\mathrm{a}} \\
-15.8 \pm 0.5^{\mathrm{wx}} & -27.3 \pm 0.6^{\mathrm{a}} \\
-13.5 \pm 0.6^{\mathrm{wx}} & -22.7 \pm 0.6^{\mathrm{c}} \\
-13.6 \pm 0.7^{\mathrm{w}} & -20.7 \pm 0.5^{\mathrm{c}} \\
-9.0 \pm 0.4^{\mathrm{w}} & -18.7^{\mathrm{qbc}} \\
-11.1 \pm 1.6^{\mathrm{wx}} & -26.5 \pm 0.4^{\mathrm{a}} \\
-12.4 \pm 0.8^{\mathrm{x}} & -26.1 \pm 0.5^{\mathrm{ab}} \\
-9.0 \pm 0.4 & - \\
& \\
-12.0 \pm 0.8^{\mathrm{wx}} & -24.1 \pm 0.5^{\mathrm{a}} \\
-11.1 \pm 0.4^{\mathrm{x}} & -25.7 \pm 0.8^{\mathrm{ab}} \\
-8.2 \pm 0.4 & -
\end{array}
$$




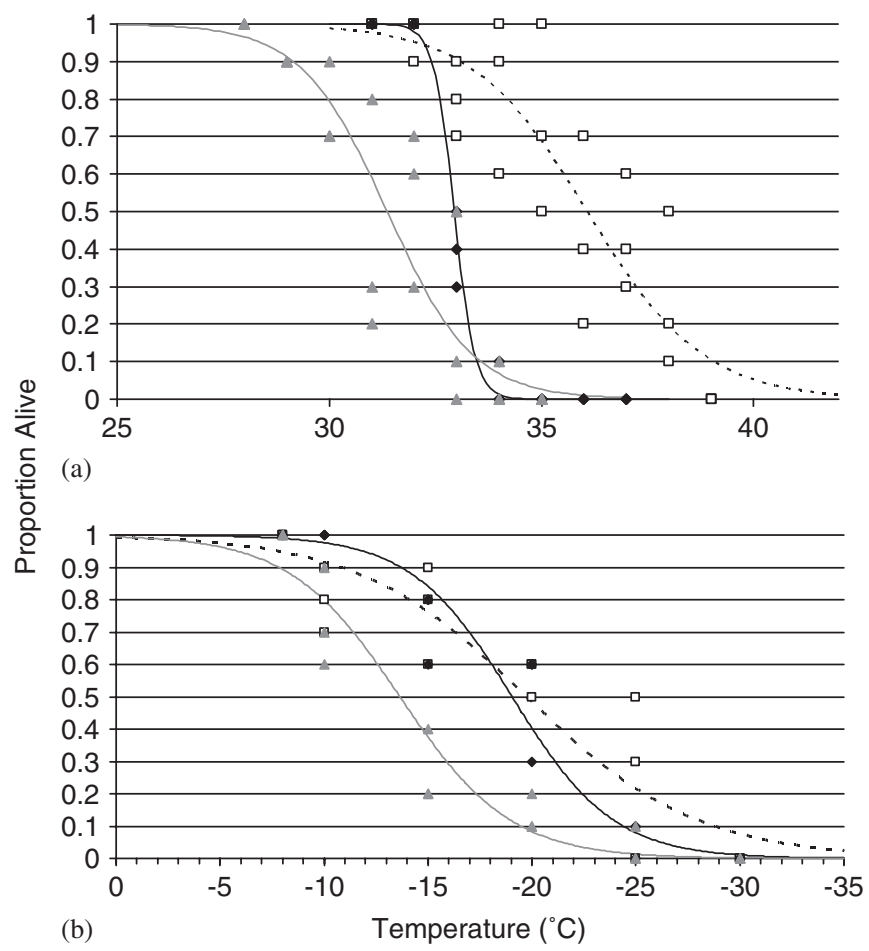

Fig. 2. (a) High temperature-related mortality (points) and fitted logistic regression models (lines) for field-fresh Collembola at Cape Hallett, Antarctica. Black diamonds, solid black line: Isotoma klovstadi (Goodness-of-fit test, 1 df: $\chi^{2}=219.2, p<0.0001 ; a=-136.3, b=4.137$, ULT50 $=33$, SEM could not be calculated); open squares, dashed line: Friesea grisea $\left(\chi^{2}=129.8, \quad p<0.0001 ; \quad a=-26.5, \quad b=0.736\right.$, ULT50 $=36.1,28.5 / 45.8$ lower/upper SEM); grey triangles, solid grey line: Cryptopygus cisantarcticus $\left(\chi^{2}=146.9, \quad p<0.0001 ; a=-31.1\right.$, $b=0.993$, ULT50 $=31.4,24.6 / 40.0$ ). (b) Low temperature-related mortality (points) and fitted logistic regression models (lines) for field-fresh Collembola at Cape Hallett, Antarctica. Black diamonds, solid black line: Isotoma klovstadi $\left(\chi^{2}=150.5, \quad p<0.0001 ; \quad a=-7.8, \quad b=-0.411\right.$, LLT50 $=-19.1,-19.1 /-19.0)$; open squares, dashed line: Friesea grisea $\left(\chi^{2}=94.7, p<0.0001 ; a=-4.8, b=-0.245\right.$, LLT50 $=-19.8,-19.8 /$ $-19.7)$; grey triangles, solid grey line: Cryptopygus cisantarcticus $\left(\chi^{2}=122.9, p<0.0001 ; a=-5.2, b=-0.377\right.$, LLT50 $=-13.6,-13.7 /$ -13.6). $a$ and $b$ refer to coefficients in Eq. (1).

\subsection{Critical thermal limits}

Critical thermal minima and maxima of all three species are summarised in Table 2. All three species had sub-zero $\mathrm{CTmin}_{\text {onset, }}$ and individuals of all three species were observed to freeze during CTmin runs (I. klovstadi: 20/60; C. cisantarcticus: $6 / 60 ; F$. grisea: $3 / 60$ individuals). In the case of $I$. klovstadi, 15 of the 20 animals that froze did so at a temperature at which they were still active. All $C$. cisantarcticus and $F$. grisea individuals that froze did so at a temperature lower than their $\mathrm{CTmin}_{\text {onset }}$. CTmin ${ }_{\text {onset }}$ did not differ significantly between $C$. cisantarcticus and F. grisea, but mean $\mathrm{CTmin}$ onset was significantly lower in I. klovstadi $\left(F_{2,146}=286.35, p<0.001\right)$. CTmin onset $_{\text {did not }}$ vary across the season in $F$. grisea or $C$. cisantarcticus (Table 2), but in I. klovstadi, CTmin onset was significantly higher in the later parts of the summer compared with the sampling dates in November and early December (species $\times$ date interaction: $\left.F_{6,146}=8.83, p<0.001\right)$.

$\mathrm{CTmin}_{\text {recovery }}$ differed between all three species and showed the same rank-order pattern as $\mathrm{CTmin}_{\text {onset }}$ $\left(F_{2,134}=314.72, \quad p<0.001\right.$; Table 2). By contrast with $\mathrm{CTmin}_{\text {onset }}, \mathrm{CTmin}$ recovery was significantly lower in the last two sampling times in $F$. grisea and C. cisantarcticus than in the first, although $C T \min _{\text {recovery }}$ did not differ across the season in I. klovstadi (Table 2; species $\times$ date: $F_{6,134}=3.55$, $p=0.003$ ). For individuals for which all critical limit measures were available, $\mathrm{CT} \mathrm{min}_{\text {recovery }}$ was significantly positively correlated with $\mathrm{CTmin}_{\text {onset }}$ in all three species (Pearson's correlation coefficient, $p<0.001$ in all cases).

Prior exposure to a CTmin run did not affect the mean CTmax of I. klovstadi collected on 20 December (when the most individuals froze; mean of CTmin individuals $=32.4 \pm 0.2^{\circ} \mathrm{C}, n=4$, mean of fresh replacements $=$ $32.4 \pm 0.2^{\circ} \mathrm{C}, n=11$ ), so CTmax of both CTmin and replacement individuals were pooled. Cryptopygus cisantarcticus had a significantly lower CTmax than I. klovstadi, which in turn had a CTmax significantly lower than that of $F$. grisea (Table 2; $F_{2,144}=176.2, p<0.001$ ). CTmax did not change within the season in $F$. grisea, but there was a significant change in both I. klovstadi and C. cisantarcticus (Table $2 ;$ species $\times$ date: $F_{6,144}=8.7, \quad p<0.001$ ). In I. klovstadi, this change was not consistent across the season (Table 2), whereas in $C$. cisantarcticus the midseason sampling dates had higher CTmax, which coincided with the warmest part of the summer (see below). CTmax was significantly negatively correlated with $\mathrm{CTmin}$ onset in I. klovstadi ( $r=-0.44, p=0.009, n=34)$, although not in the other two species (Pearson's correlation coefficient, $p>0.1$ ), and CTmin ${ }_{\text {recovery }}$ and CTmax were not correlated in any of the species (Pearson's correlation coefficient, $p>0.1$.

\subsection{Haemolymph osmolality and thermal hysteresis activity}

Haemolymph osmolality and thermal hysteresis activity of I. klovstadi and C. cisantarcticus were measured on six occasions throughout the summer season (Table 3). Haemolymph osmolality of $C$. cisantarcticus increased steadily from November to January, and contrasted with thermal hysteresis activity, which decreased as the season progressed (Table 3). Haemolymph thermal hysteresis activity in C. cisantarcticus was low (less than $0.5^{\circ} \mathrm{C}$ of hysteresis), but present throughout the season in both I. klovstadi and C. cisantarcticus (Table 3). In contrast to C. cisantarcticus, osmolality and thermal hysteresis in I. klovstadi did not show any systematic changes across the season, although values for individual sampling dates differed significantly (Table 3). Haemolymph osmolality of both $C$. cisantarcticus and I. klovstadi was not significantly correlated with environmental temperature conditions (Pearson's correlation coefficient, $p>0.05$ in both cases).

$F$. grisea had rapidly coagulating and readily oxidised haemolymph which resulted in fouling of the sample wells 
Table 2

Critical thermal minima and maxima of three species of Collembola at Cape Hallett, Antarctica, over the 2002/2003 summer. Within species, mean values with the same superscript letters do not differ significantly, an absence of letters within a group indicates no significant difference (see text for statistics). Individuals that froze during the CTmin assessments were excluded from the analyses presented here

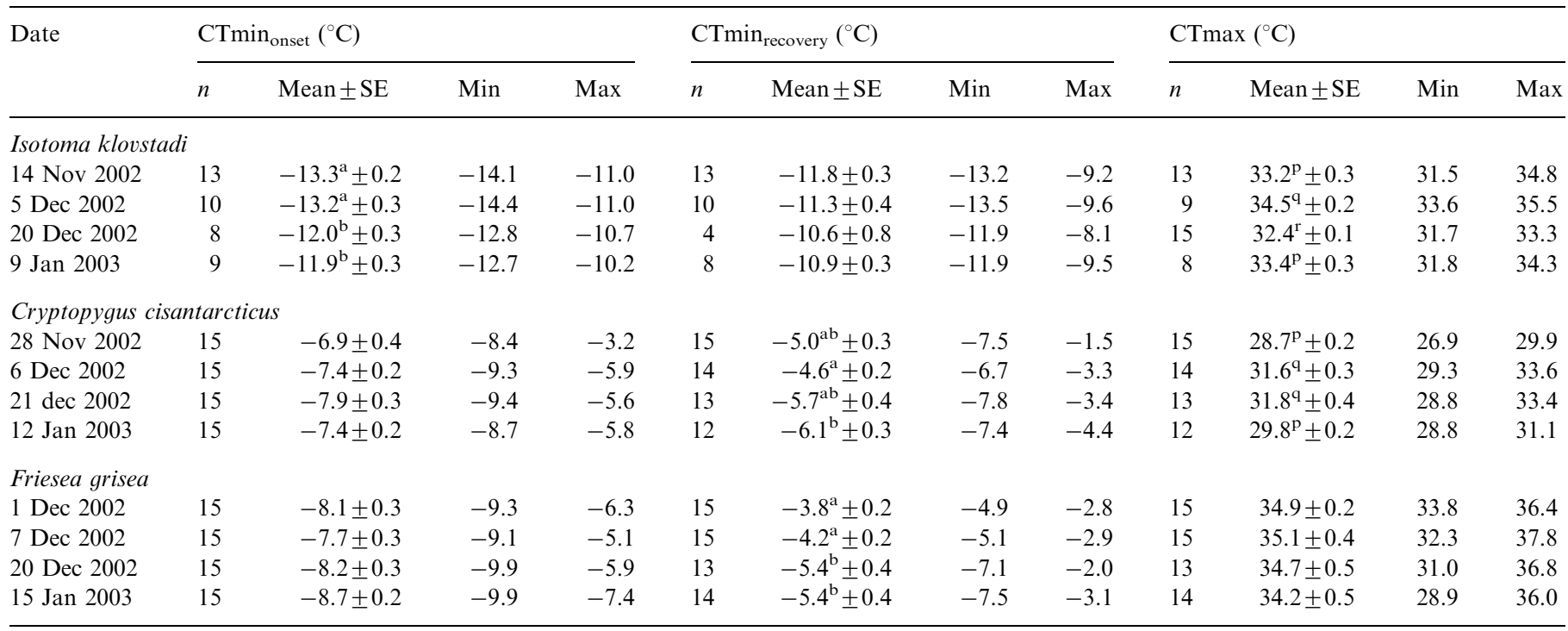

Table 3

Mean haemolymph osmolality and thermal hysteresis activity of field-fresh Isotoma klovstadi and Cryptopygus cisantarcticus in the 2002/2003 summer at Cape Hallett, Antarctica. Within species, values with the same letter are not statistically significantly different (osmolality: $I$. klovstadi: $F_{5,69}=10.43$, $p<0.0001$, C. cisantarcticus: $F_{5,59}=9.09, p<0.0001$; thermal hysteresis: $I$. klovstadi: $F_{5,69}=11.93, p<0.0001$, C. cisantarcticus: $\left.F_{5,59}=11.30, p<0.0001\right)$

\begin{tabular}{|c|c|c|c|c|c|}
\hline Date & $N$ & $\begin{array}{l}\text { Mean haemolymph } \\
\text { osmolality }(\mathrm{mOsm} \pm \mathrm{SE})\end{array}$ & Minimum (mOsm) & Maximum (mOsm) & $\begin{array}{l}\text { Mean haemolymph thermal } \\
\text { hysteresis }\left({ }^{\circ} \mathrm{C} \pm \mathrm{SE}\right)\end{array}$ \\
\hline \multicolumn{6}{|c|}{ Isotoma klovstadi } \\
\hline 19 Nov 2002 & 25 & $698^{\mathrm{ac}} \pm 4$ & 665 & 745 & $0.29^{\mathrm{p}} \pm 0.01$ \\
\hline 2 Dec 2002 & 10 & $680^{\mathrm{ab}} \pm 11$ & 601 & 735 & $0.41^{\mathrm{q}} \pm 0.03$ \\
\hline 13 Dec 2002 & 10 & $663^{\mathrm{b}} \pm 9$ & 627 & 701 & $0.45^{\mathrm{q}} \pm 0.03$ \\
\hline 23 Dec 2002 & 10 & $665^{\mathrm{b}} \pm 7$ & 632 & 706 & $0.34^{\mathrm{pr}} \pm 0.02$ \\
\hline 6 Jan 2003 & 10 & $717^{\mathrm{cd}} \pm 13$ & 669 & 811 & $0.40^{\mathrm{qr}} \pm 0.02$ \\
\hline 18 Jan 2003 & 10 & $735^{\mathrm{d}} \pm 7$ & 601 & 771 & $0.32^{\mathrm{pr}} \pm 0.02$ \\
\hline \multicolumn{6}{|c|}{ Cryptopygus cisantarcticus } \\
\hline 25 Nov 2002 & 15 & $700^{\mathrm{ab}} \pm 9$ & 666 & 774 & $0.38^{\mathrm{pq}} \pm 0.02$ \\
\hline 2 Dec 2002 & 10 & $672^{a} \pm 8$ & 619 & 701 & $0.39^{\mathrm{p}} \pm 0.01$ \\
\hline 13 Dec 2002 & 10 & $711^{\mathrm{abc}} \pm 6$ & 689 & 739 & $0.32^{\mathrm{qr}} \pm 0.01$ \\
\hline 23 Dec 2002 & 10 & $726^{\mathrm{bc}} \pm 11$ & 673 & 793 & $0.27^{\mathrm{r}} \pm 0.02$ \\
\hline 6 Jan 2003 & 10 & $751^{c} \pm 12$ & 686 & 802 & $0.28^{\mathrm{r}} \pm 0.01$ \\
\hline 17 Jan 2003 & 10 & $752^{\mathrm{c}} \pm 13$ & 709 & 861 & $0.29^{\mathrm{r}} \pm 0.01$ \\
\hline
\end{tabular}

and the micropipette, so haemolymph osmolality was determined on only a single occasion. Mean $( \pm$ SEM $)$ osmolality $(n=5)$ on 27 November was $800 \pm 36$ mOsm. Some thermal hysteresis $\left(0.44 \pm 0.02^{\circ} \mathrm{C}\right)$ was also observed in $F$. grisea, but oxidation of the haemolymph made the observation of individual crystals difficult.

\subsection{Desiccation resistance, desiccation recovery and osmoregulation}

Control animals of all three species (held above distilled water) showed less than $10 \%$ mortality over more than $5 \mathrm{~h}$ in the experimental set-up, confirming that observed mortality in individuals held in the presence of silica gel was a result of desiccation stress rather than handling. The maximum time survived above silica gel was $90 \mathrm{~min}$ for C. cisantarcticus, $210 \mathrm{~min}$ for I. klovstadi and $225 \mathrm{~min}$ for F. grisea (Fig. 3). Time to $50 \%$ mortality was significantly greater in the latter species than in C. cisantarcticus, and did not differ significantly between I. klovstadi and F. grisea (based on overlapping $95 \%$ confidence intervals).

The $3 \mathrm{~h}$ desiccation treatment resulted in a significant loss of body water in I. klovstadi, which was slowly recovered in the presence of liquid water, but not in a saturated atmosphere (Fig. 4A), suggesting that $I$. klovstadi is unable to absorb atmospheric water vapour. Desiccation 


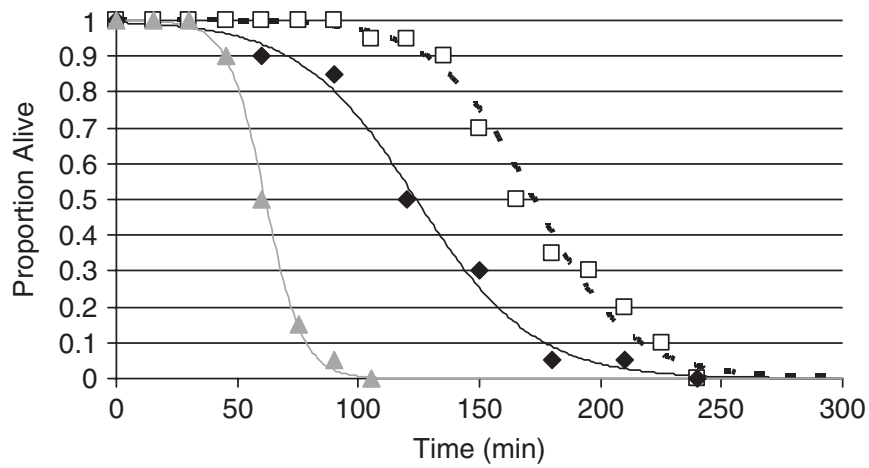

Fig. 3. Time to mortality of three Collembola species from Cape Hallett, Antarctica, when held at $20^{\circ} \mathrm{C}$ above silica gel. Lines are fitted logistic regression curves. Black diamonds, solid black line: Isotoma klovstadi (Goodness of fit test, $1 \mathrm{df}: \chi^{2}=120.3, p<0.0001$ ); open squares, dashed line: Friesea grisea $\left(\chi^{2}=243.7, p<0.0001\right)$; grey triangles, solid grey line: Cryptopygus cisantarcticus $\left(\chi^{2}=151.1, p<0.0001\right)$.

also led to increased haemolymph osmolality, which showed a similar pattern of recovery (free water) or lack of recovery (water vapour; Fig. 4B). Three hours after access to free water, water content of springtails had increased to pre-desiccation levels. Paradoxically, haemolymph osmolality was high during this period, although haemolymph osmolality was significantly negatively correlated with water content in general (Pearson's $r=-0.77$, $p=0.026, n=8)$.

After both acclimation and desiccation, there was a strong bias towards low group SCPs (Fig. 5). A switch to high group SCPs took place upon removal to recovery conditions, which was manifest both in animals with access to free water and those only with access to water vapour (Fig. 5).

With the exception of a $53-58 \mathrm{kDa}$ protein species recorded during recovery (but not before or immediately after desiccation), no evidence was found of production of novel protein species by $I$. klovstadi during exposure to or recovery from desiccation (Table 4; see below).

\subsection{Total protein analysis}

The most common and qualitatively abundant protein species detected in total protein extracts of I. klovstadi was in the region of 79-84 kDa (Fig. 6, Table 5). High levels of a higher molecular mass species $(152-162 \mathrm{kDa})$ were also present in many samples (Fig. 6, Table 5). Other protein species were present (Fig. 4), although not in high quantities, and there were no systematic changes in presence/absence across the season (Table 5) or in response to heat or desiccation stress (Table 6). In preliminary Western analyses, both the 79-84 kDa and 152-162 kDa species in some samples cross-reacted with a mouse antiHsp70 antibody. The 79-84 kDA species also cross-reacted with a mouse anti-Hsp90 antibody (results not shown).

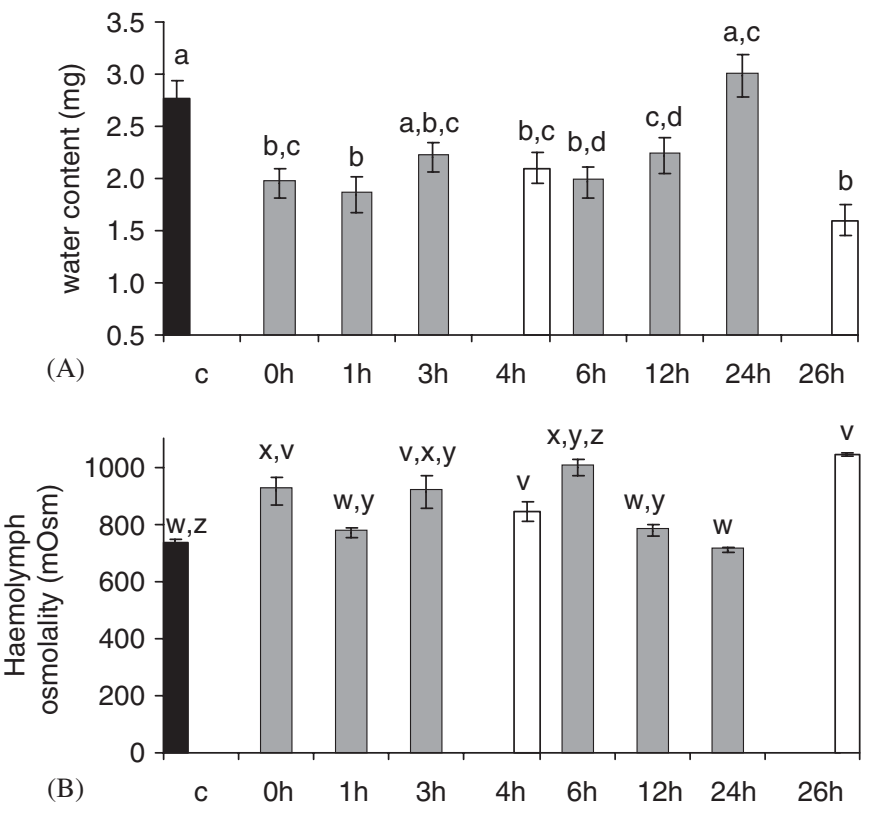

Fig. 4. Least-square mean water content (A, after ANCOVA with dry body mass as covariate; \pm standard error) and mean haemolymph osmolality (B, \pm standard error) of Isotoma klovstadi before (solid bars) and after desiccation $(0 \mathrm{~h}$, hatched bars), and during recovery with liquid water available (hatched bars) and in 100\% relative humidity (open bars). Similar letters indicate homogeneous groups (Tukey's HSD $p<0.05$; Water content: $F_{8,17}=9.282, p<0.0001, n=3$ for each treatment; Osmolality: $F_{8,32}=15.502, p<0.0001, n=5$ for all treatments except $3 \mathrm{~h}$ and $26 \mathrm{~h}$, for which $n=3$ ).

\subsection{Thermal microenvironments at Cape Hallett}

Fig. 7 indicates the high level of daily variability in temperatures at Cape Hallett, and the extent to which snow cover buffers the environmental temperatures from the otherwise strong daily cycles. The maximum microclimate temperature recorded at Cape Hallett during the 2002/03 summer was $36.6^{\circ} \mathrm{C}$ at Isotoma site 1 at $15 \mathrm{~h} 10$ on 10 December 2002. The minimum temperature was $-12.9^{\circ} \mathrm{C}$ at the same site on 2 December 2002. Summary temperature data for the three habitats at Cape Hallett for the summer of 2002/2003 are presented in Figs. 8 and 9 and in Table 7. The average thermal environment remained remarkably stable over the 10 week period of recording, with minimum temperatures at the end of the summer generally about $5{ }^{\circ} \mathrm{C}$ warmer than those measured at the beginning of the season (Fig. 8). Concomitant air temperatures varied from a mean of $-6.6^{\circ} \mathrm{C}(\max 0.6$, $\mathrm{min}-13.5$ ) in the last 2 weeks of November 2002 to a mean of $-1.1{ }^{\circ} \mathrm{C}(\max 6.1, \min -9.6)$ in the first 2 weeks of January 2003 (data from NIWA automatic weather station, Cape Hallett; Ian Hawes, pers. comm.).

The I. klovstadi habitats on the scree slope were the only data logger sites where microclimate temperatures approached potentially lethal levels during the summer, with temperatures crossing the SCP5 threshold of all three 

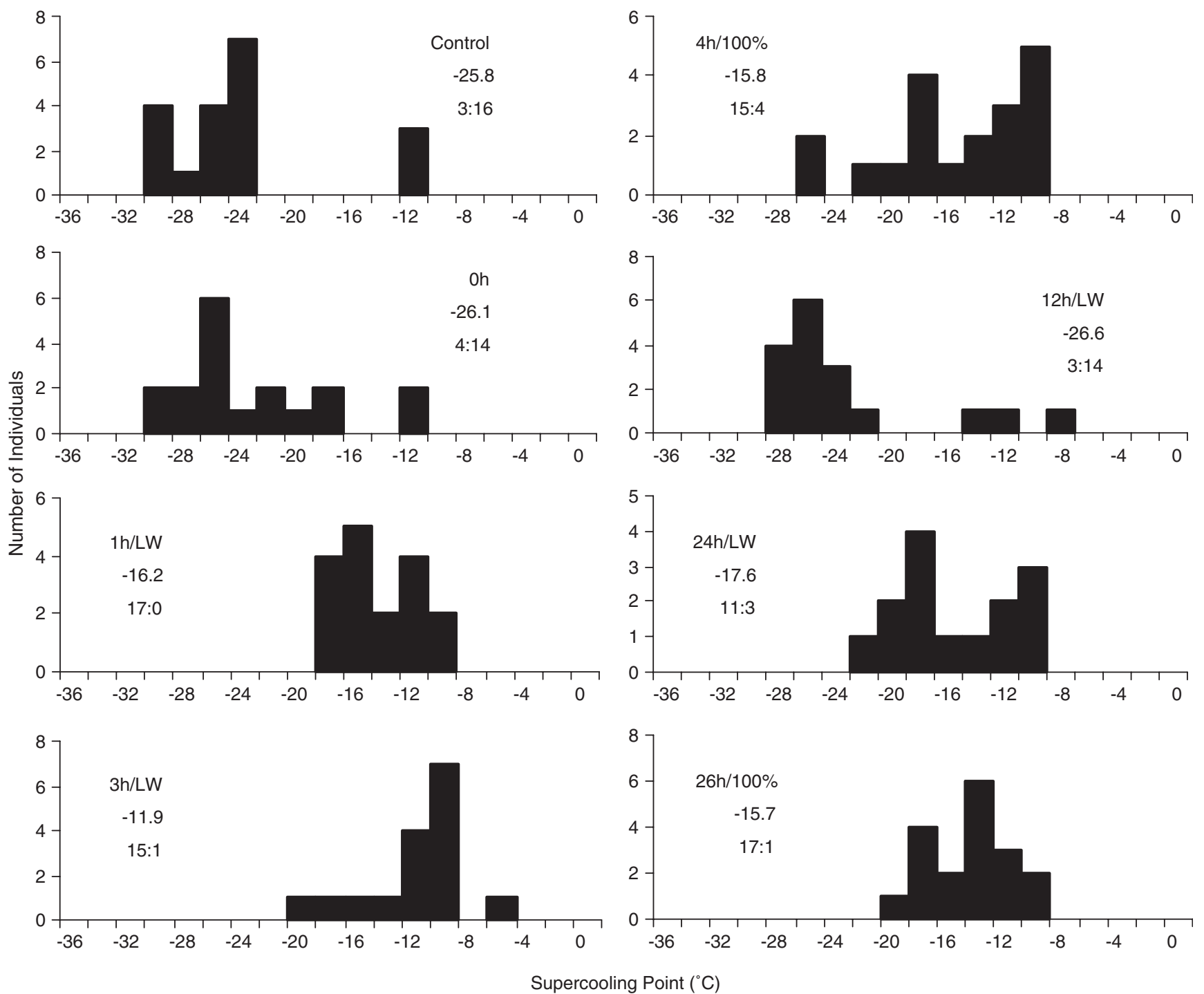

Fig. 5. Supercooling point distributions of Isotoma klovstadi in response to desiccation and recovery in the presence of liquid water (LW) and in $100 \%$ RH. Median and HG:LG ratio is given for each.

Table 4

Summary of presence/absence of protein species from SDS-PAGE of laboratory-acclimated Isotoma klovstadi collected at Cape Hallett, Antarctica, in response to desiccation and during recovery (hours) in the presence of liquid water or $100 \% \mathrm{RH}$

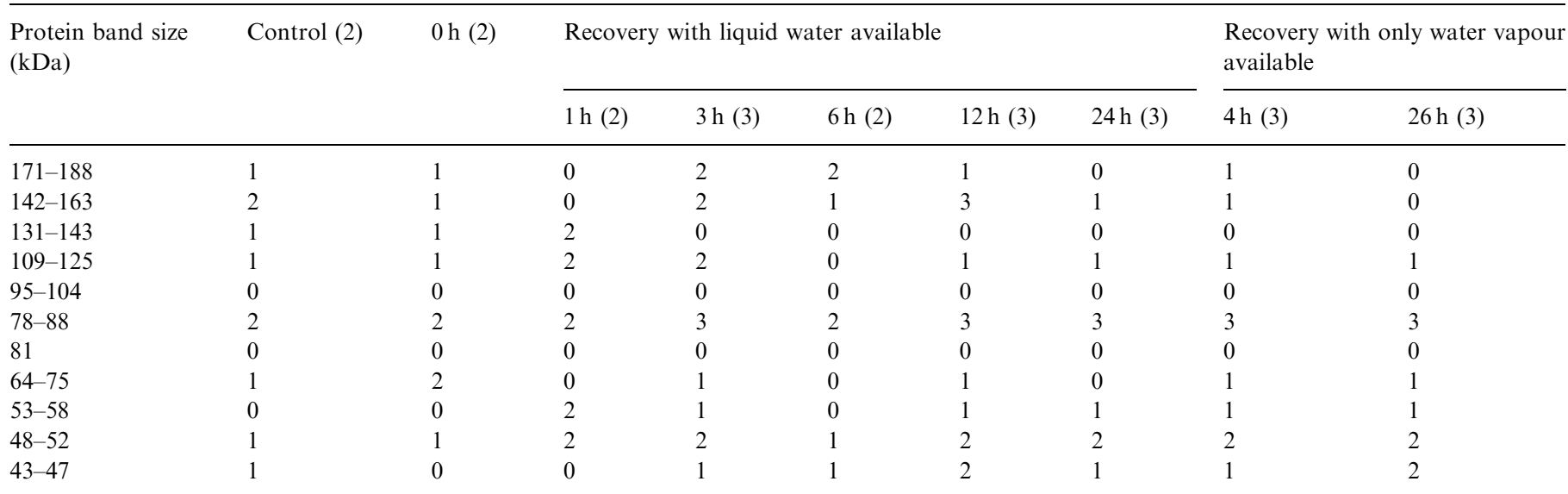

Numbers in parentheses indicate number of samples from each treatment. 
species on a number of occasions during the summer (Table 8). Microclimate temperatures did not drop below the SCP50 or LLT of any species. Temperatures above

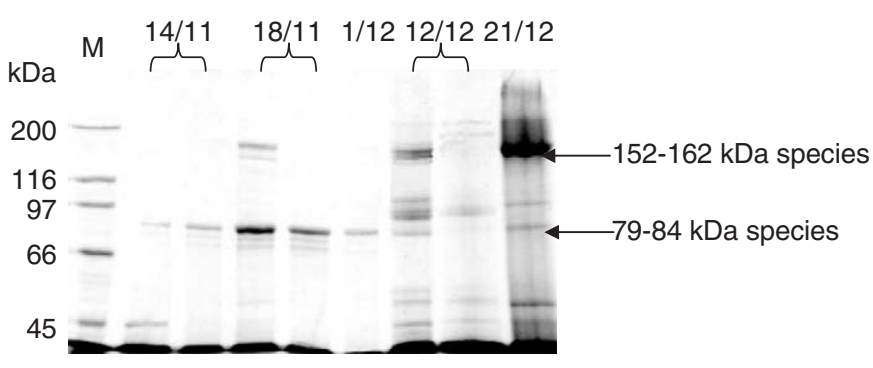

Fig. 6. Coomassie-stained SDS-PAGE gel (10\% polyacrylamide) of total protein extracts from $0.035 \mathrm{mg}$ fresh mass Isotoma klovstadi collected at Cape Hallett, Antarctica, across the 2002/2003 summer (the dates of sampling are indicated above each lane or lanes). M: molecular mass marker lane (the size of the markers are indicated on the left-hand side of the gel). The positions of the major species detected are indicated by arrows on the right- hand side of the gel. the ULT5 and ULT50 of all three species were also recorded in this habitat (Table 8). ULT thresholds for I. klovstadi and $F$. grisea (both of which occupy this habitat) were only occasionally crossed, but the thresholds for $C$. cisantarcticus were frequently experienced. The maximum cooling rates recorded in microclimates over the summer were at the I. klovstadi site 1, where a cooling rate of $0.24^{\circ} \mathrm{C} \mathrm{min}^{-1}$ was recorded for the hour preceding $16 \mathrm{~h} 15$ on 10 December 2002 across $10{ }^{\circ} \mathrm{C}$ (part of a cycle in which the microclimate temperature decreased from 25.2 to $-1.0^{\circ} \mathrm{C}$ in $12 \mathrm{~h}, 0.04{ }^{\circ} \mathrm{Cmin}^{-1}$ ). The maximum cooling rate over 1 hour at the $0^{\circ} \mathrm{C}$ threshold was $0.17^{\circ} \mathrm{C} \mathrm{min}^{-1}$ at $20 \mathrm{~h} 15$ on 16 November 2002, part of a cycle in which the temperature decreased from 12.9 to $-7.9^{\circ} \mathrm{C}$ in $9 \mathrm{~h}\left(0.04{ }^{\circ} \mathrm{Cmin}^{-1}\right)$. Cooling rates in the two algal flats habitats were relatively stable across temperature thresholds, whereas in scree slope habitat, cooling rate was slower at lower temperatures (Fig. 9).

Table 5

Summary of presence/absence of protein species from SDS-PAGE of field fresh I. klovstadi collected at Cape Hallett, Antarctica, across the 2002/2003 summer

\begin{tabular}{|c|c|c|c|c|c|c|c|}
\hline \multirow[t]{2}{*}{ Protein Band Size (kDa) } & \multicolumn{6}{|l|}{ Date } & \multirow[t]{2}{*}{ Overall number of samples (17) } \\
\hline & $14 / 11(2)$ & $18 / 11(4)$ & $1 / 12(3)$ & $12 / 12(3)$ & $21 / 12(3)$ & $6 / 1(2)$ & \\
\hline $171-188$ & 0 & 1 & 1 & 1 & 1 & 1 & 5 \\
\hline $142-163$ & 0 & 3 & 1 & 3 & 3 & 2 & 12 \\
\hline $131-143$ & 0 & 3 & 0 & 2 & 1 & 0 & 6 \\
\hline $109-125$ & 0 & 1 & 1 & 2 & 2 & 1 & 7 \\
\hline $95-104$ & 0 & 2 & 1 & 3 & 3 & 1 & 10 \\
\hline $78-88$ & 2 & 4 & 3 & 2 & 3 & 2 & 16 \\
\hline 81 & 2 & 2 & 1 & 1 & 0 & 0 & 6 \\
\hline $64-75$ & 1 & 4 & 0 & 1 & 0 & 2 & 8 \\
\hline $53-58$ & 0 & 0 & 3 & 1 & 0 & 0 & 4 \\
\hline $48-52$ & 0 & 3 & 2 & 3 & 2 & 1 & 11 \\
\hline $43-47$ & 1 & 1 & 1 & 3 & 2 & 1 & 9 \\
\hline
\end{tabular}

Numbers in parentheses indicate number of samples at each date.

Table 6

Summary of presence/absence of protein species from SDS-PAGE of lab-acclimated Isotoma klovstadi collected at Cape Hallett, Antarctica, in response to temperature and desiccation treatments

\begin{tabular}{|c|c|c|c|c|c|c|c|c|c|}
\hline \multirow[t]{2}{*}{ Protein band size $(\mathrm{kDa})$} & \multicolumn{8}{|l|}{ Treatment } & \multirow[t]{2}{*}{ Overall number of samples (25) } \\
\hline & Control (3) & Des (4) & Slow (4) & $28^{\circ} \mathrm{C}(2)$ & $0^{\circ} \mathrm{C}(5)$ & $-5^{\circ} \mathrm{C}(2)$ & $-5 \mathrm{~g}(3)$ & $-9^{\circ} \mathrm{C}(2)$ & \\
\hline $171-188$ & 0 & 1 & 2 & 1 & 1 & 1 & 1 & 0 & 7 \\
\hline $142-163$ & 0 & 0 & 0 & 0 & 0 & 0 & 0 & 0 & 0 \\
\hline $131-143$ & 0 & 0 & 0 & 0 & 0 & 0 & 0 & 0 & 0 \\
\hline $109-125$ & 3 & 2 & 1 & 1 & 2 & 2 & 2 & 2 & 15 \\
\hline 95-104 & 2 & 3 & 2 & 1 & 2 & 2 & 3 & 2 & 17 \\
\hline $78-88$ & 2 & 4 & 4 & 2 & 5 & 2 & 3 & 2 & 24 \\
\hline 81 & 0 & 0 & 0 & 0 & 0 & 0 & 0 & 0 & 0 \\
\hline $64-75$ & 1 & 0 & 0 & 0 & 0 & 0 & 0 & 0 & 1 \\
\hline $53-58$ & 2 & 3 & 1 & 2 & 2 & 2 & 3 & 3 & 18 \\
\hline $48-52$ & 1 & 1 & 0 & 0 & 0 & 1 & 1 & 1 & 5 \\
\hline $43-47$ & 1 & 1 & 0 & 1 & 1 & 1 & 1 & 1 & 7 \\
\hline
\end{tabular}

Numbers in parentheses indicate number of samples from each treatment. Des $=$ desiccation treatment; slow $=\operatorname{slow}$ cooling from +5 to $-2{ }^{\circ} \mathrm{C}\left(1^{\circ} \mathrm{C} \mathrm{h}^{-1}\right)$; $-5 \mathrm{~g}=2 \mathrm{~h}$ treatment at $-5^{\circ} \mathrm{C}$ followed by $2 \mathrm{~h}$ at $+5^{\circ} \mathrm{C}$; other treatments indicate a $2 \mathrm{~h}$ exposure to a given temperature. 


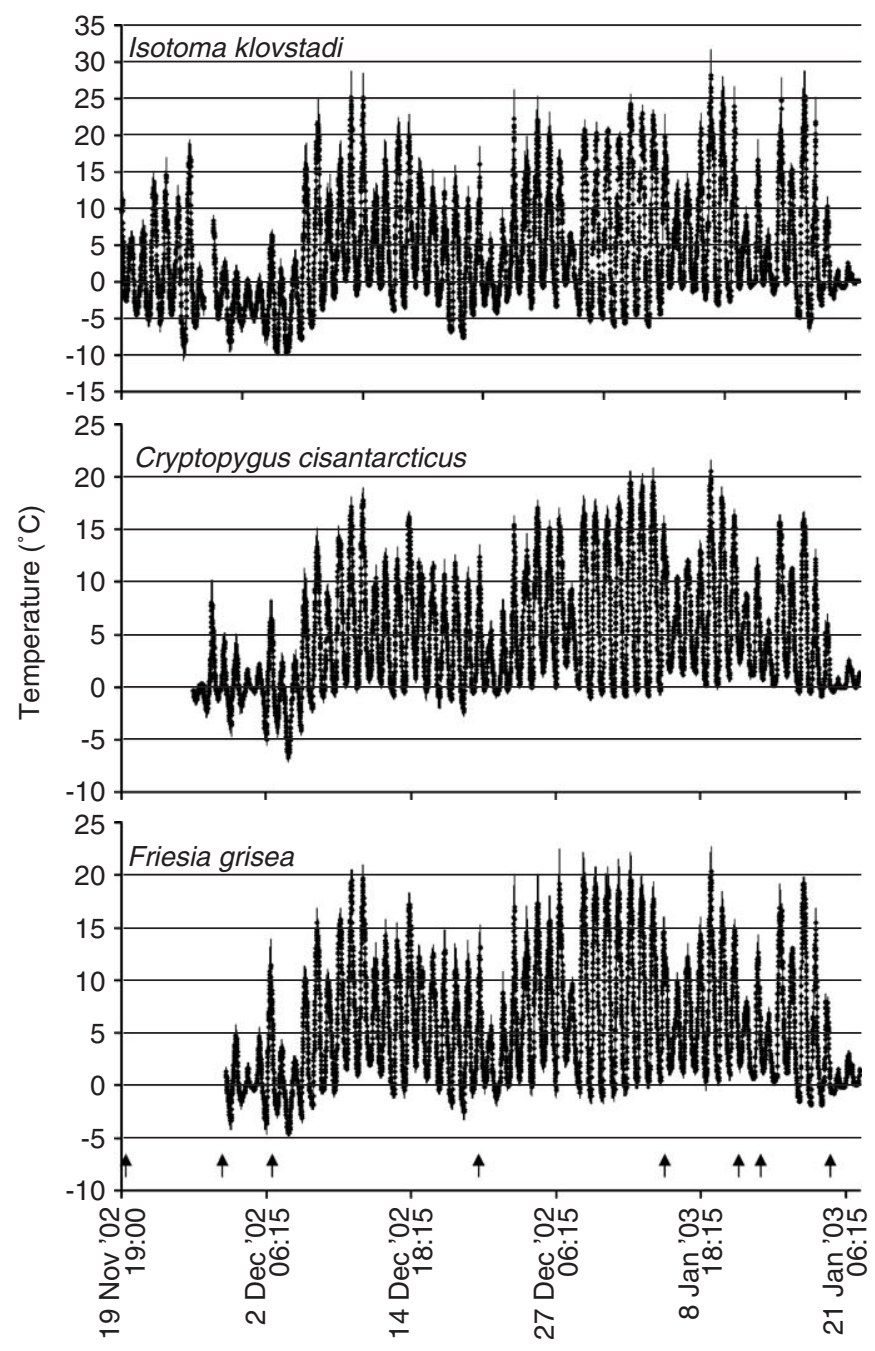

Fig. 7. Mean \pm standard error microclimate temperatures measured at 10 min intervals at representative sites for three species of Collembola at Cape Hallett, Antarctica, during the 2002/2003 summer. Isotoma klovstadi: 5 locations; Friesea grisea and Cryptopygus cisantarcticus: 3 locations. Arrows indicate major snowfall events.

Direct comparisons of the thermal environments offered by the three different habitats were made during the month of December, for which a full set of data were available for all three sites (Table 9). Cooling rates at $0{ }^{\circ} \mathrm{C}$ were fastest in the Isotoma habitat, and did not differ substantially between the other two habitats (Table 9). The greatest number of freeze-thaw cycles and events below the $-3.2{ }^{\circ} \mathrm{C}$ threshold (the highest recorded SCP) were also experienced in the scree slope habitat. The amount of time spent above $0{ }^{\circ} \mathrm{C}$ was lowest for Isotoma habitat, but there was no difference between habitats in terms of time spent above $10{ }^{\circ} \mathrm{C}$ (Table 9). The only significant relationship between stone characteristics and microclimate temperature statistics was a negative relationship between stone area (but not volume) and total time spent above $10{ }^{\circ} \mathrm{C}$ (Spearman's $r=-0.618, p<0.05, n=11 ; p>0.05$ in all other correlations).

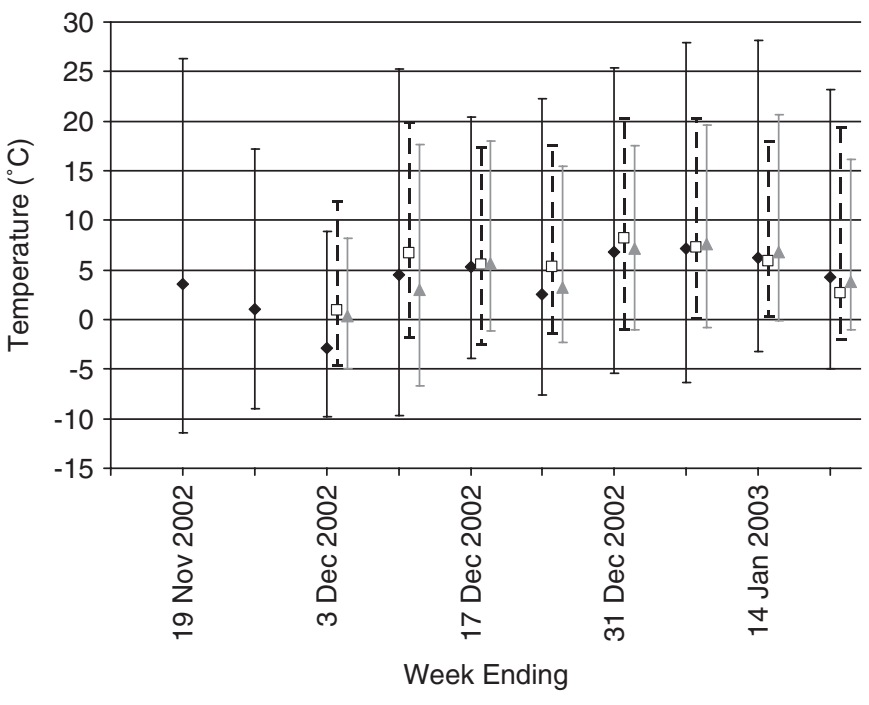

Fig. 8. Weekly mean, mean minimum and mean maximum microclimate temperatures over the 2002/2003 summer at Cape Hallett, Antarctica. Black diamonds: representative Isotoma klovstadi habitat $(n=5$ locations); open squares $=$ Friesea grisea $(n=3$ locations); grey diamonds: Cryptopygus cisantarcticus ( $n=3$ locations).

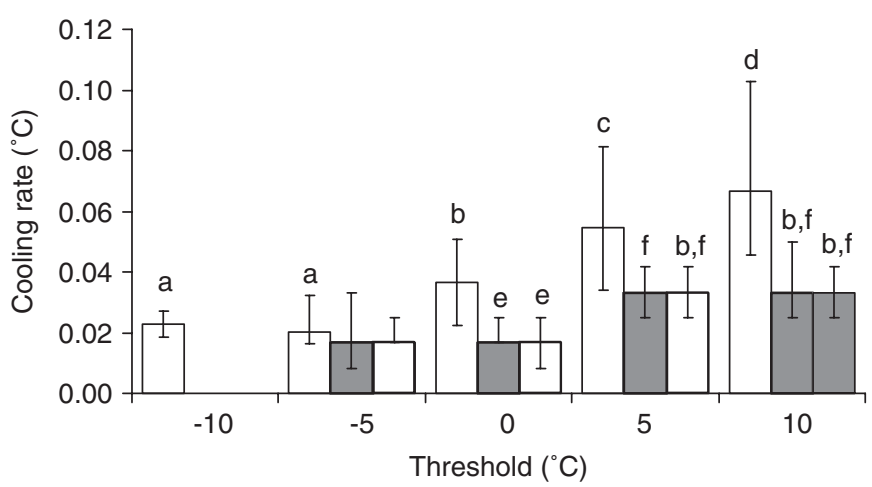

Fig. 9. Median microclimate cooling rates ( \pm quartiles) across threshold temperatures for the 2002/2003 summer at Cape Hallett, Antarctica. Open bars: representative Isotoma klovstadi habitat (5 locations); hatched bars: Friesea grisea; stippled bars: Cryptopygus cisantarcticus. Similar letters indicate homogeneous groups (within I. klovstadi comparisons, GLZ, Wald $\chi^{2}=310.6(4 \mathrm{df}), p<0.0001$; between species comparisons $(0,5$ and $10{ }^{\circ} \mathrm{C}$ only) Wald $\chi^{2}=436.1 \quad(2 \mathrm{df}), p<0.0001$; threshold $\times$ species interaction $\left(0,5\right.$ and $10^{\circ} \mathrm{C}$ only) Wald $\chi^{2}=37.67$ (4 df), $\left.p<0.0001\right)$.

\section{Discussion}

The extremely low winter temperatures experienced by Collembola during winter at Cape Hallett (see Pryor, 1962) are likely to be a primary stressor driving their physiological evolution. However, we show here that potentially lethal high and low temperatures do occur in the microhabitats during the summer. Thus, Collembola living at Cape Hallett must show resistance adaptations (sensu Precht, 1958) to survive in their environment, even during the summer. Although the period from November to January is one of large changes to the physical 
Table 7

Summary of microclimatic temperatures $\left({ }^{\circ} \mathrm{C}\right)$ collected over the 2002/2003 summer from locations representative of habitat for three species of Collembola at Cape Hallett, Antarctica. Isotoma klovstadi site 2 is approximately $100 \mathrm{~m}$ north of site 1 , and has a similar aspect and elevation. Mean, mean minimum and mean maximum were only calculated for I. klovstadi site 2 because of sample size, and the two I. klovstadi sites were not combined because of the truncated logging period for site 1

\begin{tabular}{lllll}
\hline & Cryptopygus cisantarcticus & Friesea grisea & Isotoma klovstadi Site 1 & I. klovstadi Site 2 \\
\hline Number of loggers & 3 & 3 & 2 & 3 \\
Start date & 25 Nov 2002 & 28 Nov 2002 & 16 Nov 2002 & 5 Nov 2002 \\
End date & 22 Jan 2003 & 22 Jan 2003 & 5an 2003 & 22 Jan 2003 \\
Mean \pm SEM & $4.6 \pm 0.3$ & $5.3 \pm 0.2$ & & $4.5 \pm 0.7$ \\
Median & 3 & 4 & 2.0 & 1.6 \\
Lower quartile & 8.5 & 9.5 & -2.9 & 8.2 \\
Upper quartile & 0 & 0.5 & & -1.5 \\
Mean maximum $( \pm$ SEM) & $20.7 \pm 1.0$ & $21.5 \pm 1.7$ & 36.6 & $33.4 \pm 3.9$ \\
Absolute maximum & 22.5 & 24.5 & $-4.7 \pm 0.4$ & $-10.7 \pm 0.7$ \\
Mean minimum $( \pm$ SEM) & $-6.7 \pm 0.4$ & -5.5 & -12.9 & -12 \\
Absolute minimum & -7.5 & &
\end{tabular}

Table 8

Occurrence of biological temperature thresholds in microclimates representative of Isotoma klovstadi habitat (sites 1 and 2 combined) at Cape Hallett, Antarctica over the 2002/2003 summer. SCP5 is the temperature at which $5 \%$ of individuals would be expected to freeze (from cumulative SCP data); ULT5 and ULT50 are the temperatures at which 5\% and 50\% of individuals would be expected to die from acute heat stress (from ULT data). Number of loggers refers to the number of data loggers that recorded temperatures outside the threshold, $N=5$ data loggers.

\begin{tabular}{|c|c|c|c|c|}
\hline & & \multicolumn{3}{|l|}{ Species } \\
\hline & & Isotoma klovstadi & Friesea grisea & Cryptopygus cisantarcticus \\
\hline \multirow[t]{4}{*}{ SCP5 } & Threshold value & $-7.6^{\circ} \mathrm{C}$ & $-11.2^{\circ} \mathrm{C}$ & $-9.7^{\circ} \mathrm{C}$ \\
\hline & Mean no. events & 11.6 & 1.2 & 5 \\
\hline & Max, min no. events & 23,2 & 3,0 & 10,1 \\
\hline & No. loggers & 5 & 3 & 5 \\
\hline \multirow[t]{4}{*}{ ULT5 } & Threshold value & $33^{\circ} \mathrm{C}$ & $32.1^{\circ} \mathrm{C}$ & $28.4^{\circ} \mathrm{C}$ \\
\hline & Mean no. events & 3 & 3 & 9.2 \\
\hline & Max, min no. events & 8,0 & 8,0 & 23,0 \\
\hline & No. loggers & 2 & 2 & 2 \\
\hline \multirow[t]{4}{*}{ ULT50 } & Threshold value & $32.2^{\circ} \mathrm{C}$ & $36.1^{\circ} \mathrm{C}$ & $31.4^{\circ} \mathrm{C}$ \\
\hline & Mean no. events & 1.8 & 0.4 & 5.6 \\
\hline & Max, min no. events & 5,0 & 2,0 & 15,0 \\
\hline & No. loggers & 2 & 1 & 2 \\
\hline
\end{tabular}

Table 9

Comparison of microclimatic conditions for representative habitats of three species of Collembola at Cape Hallett, Antarctica, during December 2002. Mean \pm SE is presented, with the exception of surface values, for which only two locations were monitored. $N=5$ locations for Isotoma klovstadi site, and 3 for Cryptopygus cisantarcticus and Friesea grisea sites. Comparisons were only made between habitats (not including surface) using GLZ (cooling rates) or Kruskal-Wallis rank ANOVA ( $2 \mathrm{df}, n=11)$, and means with similar superscript letters are not significantly different. Maximum cooling rate is at the $0{ }^{\circ} \mathrm{C}$ threshold

\begin{tabular}{llllll}
\hline & Surface & \multicolumn{2}{l}{ Site } & & \\
\cline { 3 - 5 } & & Isotoma & Cryptopygus & Friesea & \\
\hline Maximum cooling rate $\left({ }^{\circ} \mathrm{C}\right.$ min $\left.^{-1}\right)$ & 0.104 & $0.118^{\mathrm{a}} \pm 0.017$ & $0.05^{\mathrm{b}} \pm 0.008$ & $0.042^{\mathrm{b}} \pm 0.008$ & Wald $\chi^{2}=118.7, p<0.001$ \\
No. freeze-thaw cycles & 51.5 & $35.8^{\mathrm{a}} \pm 0.7$ & $21.3^{\mathrm{b}} \pm 6.2$ & $22^{\mathrm{b}} \pm 6.0$ & $H=7.549, p=0.023$ \\
No. cycles below $-3.2^{\circ} \mathrm{C}$ & 36.5 & $23.8^{\mathrm{a}} \pm 1.9$ & $4.3^{\mathrm{b}} \pm 0.9$ & $3.3^{\mathrm{b}} \pm 0.9$ & $H=7.813, p=0.020$ \\
Time above $0{ }^{\circ} \mathrm{C}(\min )$ & 25995 & $28326^{\mathrm{a}} \pm 778$ & $33393^{\mathrm{b}} \pm 1222$ & $35310^{\mathrm{b}} \pm 1390$ & $H=7.879, p=0.020$ \\
Time above $10^{\circ} \mathrm{C}(\min )$ & 8023 & $10724 \pm 1797$ & $6663 \pm 1031$ & $9513 \pm 1743$ & $H=0.776, p=0.679$ \\
\hline
\end{tabular}

environment, including the break-up of sea ice surrounding Cape Hallett and the beginning of snow melt, the microclimate temperature environment changes relatively little (Figs. 7 and 8). Coupled with the availability of water from large snowbanks and regular precipitation events at Cape Hallett (Sinclair, Klok, Scott and Terblanche, pers. 
obs.), this stability of microclimate conditions results in a long growing season by continental Antarctic standards (see Janetschek, 1967; Sømme, 1986; Marshall et al., 1995; Sinclair and Sjursen, 2001a, for examples from elsewhere on the continent).

\subsection{Thermal tolerances}

In common with all Antarctic Collembola studied thus far (Cannon and Block, 1988), the correspondence of LLT50 and median SCP indicate that all three species of Collembola at Cape Hallett are freeze avoiding. C. cisantarcticus and I. klovstadi both demonstrate diurnal variation in SCP, while $F$. grisea does not (see also Sinclair et al., 2003b). The lowest SCPs recorded for each species (Table 1) are lower than those recorded during summer in species from the Antarctic peninsula (Sømme and Block, 1982; Cannon and Block, 1988) and not dissimilar to those recorded for G. hodgsoni during the summer at Cape Bird $\left(5^{\circ}\right.$ south of Cape Hallett, Sinclair and Sjursen, 2001a). Although when collected under stones they had a strongly bimodal SCP distribution, individuals of I. klovstadi collected while grazing on the surface of moss had unimodally high SCPs, which lends weight to the hypothesis that high SCPs result from food in the gut (Cannon and Block, 1988; Sinclair et al., 2003b). C. cisantarcticus SCPs were higher than those described for acclimated individuals of the continental Cryptopygus sverdrupi (Sømme, 1986), but lower than those reported for fieldfresh C. antarcticus from the Antarctic Peninsula (Worland and Convey, 2001). F. grisea showed a consistently unimodal pattern of 'low group' SCPs. This contrasts with the substantial (and nearly unimodal) high SCP group that Block (1982) reported for $F$. grisea from Adelaide Island in the maritime Antarctic. F. grisea is the only circumAntarctic species of Collembola (Wise, 1967). Given the likely low or negligible rate of cross-continental dispersal, the presumed antiquity of the separations between species across the continent (Marshall and Pugh, 1996) and the differing environmental conditions between the continental and maritime Antarctic regions (Block, 1994), it is not surprising to find substantial differences between populations on opposite sides of the continent. As a predator, $F$. grisea may not ingest large quantities of ice nucleators (or may have proteolytic enzymes that destroy them), which may account for the unimodality of its SCP. $F$. grisea was the only species where LLT50 and median SCP differed, suggesting that although it may have a strong tolerance to acute low temperatures, it is susceptible to prolonged exposure. However, tolerance of prolonged periods at subzero temperatures is a necessity for surviving the Antarctic winter, so F. grisea presumably must undergo some level of seasonal acclimatisation that increases its chill tolerance(see Sømme, 1996, for further discussion of the effects of prolonged low temperature exposure). Such a separation of tolerances to acute and prolonged low temperature has been shown in temperate Collembola and other insects (Nedved, 1998; Hanc and Nedved, 1999), and although noted for Antarctic species (see Pryor, 1962; Fitzsimons, 1971; Convey and Worland, 2000), has not yet been explored in any depth.

Low levels of thermal hysteresis activity were detected in all three species of Collembola at Cape Hallett. These low levels are certainly not enough to account for the high degree of supercooling, but are similar to those described for summer-acclimated individuals of several alpine Collembola (Zettel, 1984). Although thermal hysteresis activity declined in $C$. cisantarcticus during the season, it never entirely disappeared, in contrast to G. hodgsoni, where haemolymph thermal hysteresis activity disappears entirely during the summer (although whole-animal homogenates still inhibit recrystallisation, Sinclair and Sjursen, 2001a). It is likely that, during summer, thermal hysteresis proteins may still be advantageous for preventing gut nucleation or inoculative freezing in Antarctic Collembola, but in G. hodgsoni are intracellular or associated with tissues, rather than the haemolymph. If high haemolymph osmolality is directly related to cold tolerance, osmolality may have been expected to decline over the summer as it does in G. hodgsoni (Sinclair and Sjursen, 2001a). However, no consistent patterns were observed in I. klovstadi, and osmolality actually increased in C. cisantarcticus. Similarly, there was no strong seasonal pattern in cold tolerance for either species (see below).

SCPs within high and low groups did not change systematically across the summer in any of the species we examined. However, in C. cisantarcticus and I. klovstadi, there was a seasonal shift in the HG:LG ratio, such that there were more individuals in the high group towards the end of summer (Table 1). This suggests that, in summer, the relative levels of cold tolerance in the two modes are fixed, and the animals respond to ameliorating or deteriorating thermal conditions by switching between groups, as has been demonstrated on a diurnal scale (Sinclair et al., 2003b). Seasonally, this shift between the groups could be a result of an active physiological change, or simply a coincidental shift as the proportion of the population that is actively feeding or moulting at a given time changes across the season (Worland, 2005). The substantial shift towards the low group in I. klovstadi in late December coincided with a period of low temperatures and snow (see Sinclair et al., 2003b, for discussion). Nevertheless, the extent to which the shifts in SCP from HG to LG are mediated by temperature, feeding or moulting is unclear from our data and the mechanisms for the observed SCP shifts are currently unknown for any Antarctic collembolan (Cannon and Block, 1988; Worland and Convey, 2001; Worland, 2005).

Critical thermal minima of all three species were well below $0{ }^{\circ} \mathrm{C}$, and the mean $\mathrm{CTmin}$ onset of -12 to $-13{ }^{\circ} \mathrm{C}$ for I. klovstadi (Table 2) is among the lowest chill coma temperatures recorded in any arthropod (but see Fitzsimons, 1971; Kohshima, 1984). It is unique to find a freeze avoiding species which is still potentially active at the SCP, 
which suggests that the low chill-coma temperature in I. klovstadi may be an adaptation used by cold-susceptible foraging individuals to avoid potentially lethal temperatures. CTmin ${ }_{\text {onset }}$ of I. klovstadi was significantly higher in the height of summer than earlier in the season (Table 2). This is consistent with observations of acclimatisation of $\mathrm{CTmin}_{\text {onset }}$ in response to season and altitude in other insect species (e.g. Klok and Chown, 2003). Critical thermal minima of $C$. cisantarcticus $\left(-3\right.$ to $\left.-9{ }^{\circ} \mathrm{C}\right)$ were slightly higher than the -6 to $-10^{\circ} \mathrm{C}$ reported for $C$. antarcticus on Signy island (Sømme and Block, 1982), although the latter authors used a much faster cooling rate $\left(1{ }^{\circ} \mathrm{C} \mathrm{min}{ }^{-1}\right)$ than was used here.

Within-individual CTmin ${ }_{\text {recovery }}$ was strongly correlated with $\mathrm{CTmin}_{\text {onset }}$, and I. klovstadi, which had the lowest

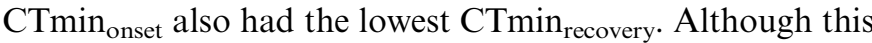
has important ecological consequences, the correlation may be the result of a common mechanism (possibly $\mathrm{Na}^{+} / \mathrm{K}^{+}$ATPase activity, see Hosler et al., 2000; Sinclair et al., 2004) determining both onset and recovery. However, significant (and systematic) seasonal changes in CTmin recovery of $C$. cisantarcticus and $F$. grisea were not mirrored in

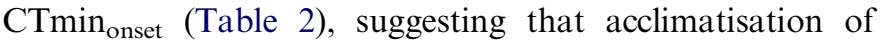
the two parameters may not be directly coupled (see Chown and Nicolson, 2004 for a review of measures of thermal tolerance and their variation). C. cisantarcticus and $F$. grisea showed a similar trend in $C T \min _{\text {recovery }}$ over the summer season, with a decrease in $\mathrm{CT} \mathrm{min}_{\text {recovery }}$ in the second part of the season, in spite of a lack of change in CTmin ${ }_{\text {onset }}$.

Because of the assumption that low temperatures are the most important environmental stress for terrestrial Antarctic arthropods, upper lethal tolerances have rarely been investigated (but see Janetschek (1967) and Fitzsimons (1971) for data on G. hodgsoni from South Victoria Land). However, our microclimate data from the scree slope sites where both I. klovstadi and F. grisea are present indicate that potentially lethal high temperatures can and do occur in the field at Cape Hallett (Table 8). Both acute (CTmax) and prolonged ( $2 \mathrm{~h}$ exposure in moist conditions) exposure to high temperatures indicate that all three species of Collembola can survive temperatures in excess of $30^{\circ} \mathrm{C}$, and that the rank order of tolerance to high temperatures is $F$. grisea (most tolerant) $>I$. klovstadi $>C$. cisantarcticus (least tolerant). These upper temperature limits are in a similar range to those described for Arctic Collembola (Hodkinson et al., 1996). Overall, F. grisea is the species most tolerant to temperature extremes, followed by I. klovstadi and C. cisantarcticus. However, I. klovstadi has the widest thermal activity window (difference between mean CTmin and mean CTmax $=47.7^{\circ} \mathrm{C}$ in December 2002), possibly allowing better behavioural exploitation of the thermal landscape than $F$. grisea $\left(43^{\circ} \mathrm{C}\right.$ in December 2002) or C. cisantarcticus $\left(39.7^{\circ} \mathrm{C}\right)$. Hayward et al. (2004) reported that $F$. grisea from Rothera on the Antarctic peninsula has greater environmental tolerances and shows less movement across the habitat than $C$. antarcticus, and suggest that the lower tolerances of $C$. antarcticus necessitate movement to avoid potentially lethal conditions. At Cape Hallett, $F$. grisea has greater tolerances than $C$. cisantarcticus, which is consistent with Hayward et al.'s (2004) report. Assuming that other factors such as food availability and interspecific competition are equal, it seems likely that, during the summer, high temperatures may prevent C. cisantarcticus from occupying the scree slope habitat.

\subsubsection{Desiccation, recovery and osmoregulation}

Haemolymph osmolality of all three species of Collembola in this study (ca. $700 \mathrm{mOsm} \mathrm{kg}^{-1}$ ) was higher than that measured in summer-acclimatised Collembola in Antarctica (Block and Harrisson, 1995; Sinclair and Sjursen, 2001a) and elsewhere (Zettel, 1984; Sinclair and Chown, 2002), which tend to be below $500 \mathrm{mOsm} \mathrm{kg}{ }^{-1}$. Winter-adapted Collembola show osmolalities comparable to (or higher than) those we measured (Meier and Zettel, 1997; Sinclair and Sjursen, 2001a), suggesting that the high osmolality of the Cape Hallett species may be associated with their retention of cold hardiness during the summer. There was a significant increase in haemolymph osmolality of both C. cisantarcticus and I. klovstadi across the season (Table 3), which may correspond to changing water availability as the local sources of water (snowbanks) were depleted by January (not all habitats receive meltwater from the larger, permanent snowbanks, B.J. Sinclair, pers. obs.).

Collembola are highly susceptible to desiccation stress (Hopkin, 1997). Low water availability in their environment means that continental Antarctic Collembola might be expected to be more desiccation tolerant than their mesic counterparts. Nevertheless, water stress is thought to substantially influence distributions of and interactions between Antarctic arthropods at both small (Janetschek, 1967; Sinclair and Sjursen, 2001b; Hayward et al., 2004) and large (Kennedy, 1993) scales, as well as being potentially important in terms of species' responses to precipitation pattern changes as a result of climate change (Convey et al., 2003). Of the three species examined at Cape Hallett, C. cisantarcticus was the least desiccation tolerant, and mortality begins much earlier in I. klovstadi than $F$. grisea, although the maximum tolerances of the two are similar. This is consistent with both the small-scale distribution of the three species (C. cisantarcticus is not found in the much drier scree slope habitat), and (unlike the SCP data) is concordant with data from the Antarctic Peninsula, where Hayward et al. (2004), infer from distribution responses that $F$. grisea is more desiccation tolerant than C. antarcticus.

We were able to investigate osmoregulation and recovery from desiccation stress more thoroughly in I. klovstadi than in C. cisantarcticus or F. grisea. Like most Collembola (Hopkin, 1997), I. klovstadi is a poor osmoregulator, with haemolymph osmolality increasing considerably after desiccation. Recovery of body water was reasonably rapid when liquid water was available, but there was a lag in the reduction of haemolymph osmolality. In Drosophila melanogaster, the regulation of ions is an important aspect of 
recovery from desiccation stress (Folk et al., 2001), so the observed lag in I. klovstadi could result from a mechanism preventing loss of ions during desiccation in the less sophisticated collembolan osmoregulatory system. Water content and osmolality did not change when the Collembola were only allowed access to a saturated atmosphere, suggesting that, unlike Collembola from mesic environments (Bayley and Holmstrup, 1999; Holmstrup et al., 2001), I. klovstadi is unable to absorb atmospheric water vapour. After acclimation and desiccation, SCPs were largely in the low group (as may be expected for starved animals, Sinclair et al., 2003b), but there was a shift to the high group upon removal from the desiccating conditions. This SCP shift occurred in animals with access to both free water and water vapour, suggesting that it is not simply an effect of drinking (as has been described for C. antarcticus; Cannon et al., 1985), but is part of the recovery process. The SCP of I. klovstadi kept in constant dark or constant light under standard thermal regimes did not differ between night and day (B.J. Sinclair, unpublished observations), ruling out the possibility of confounding effects from an endogenous circadian rhythm in SCP.

\subsubsection{Total protein analysis}

With the exception of a ca. 53-58 kDa species apparently expressed during recovery from desiccation stress (Table 4), there were no consistent qualitative changes in I. klovstadi protein levels in response to temperature or desiccation treatments. The most consistently detected protein band was approximately $83 \mathrm{kDa}$ in size, and in some preliminary Western analyses on certain samples, this protein species exhibited cross-reaction with a Mouse anti-Hsp90 antibody, as did the larger (ca. $140 \mathrm{kDa}$ ) species that was present in a large proportion of samples. Hsp90 is the most commonly expressed constitutive heat shock protein in animal cells (Csermely et al., 1998), and in Drosophila melanogaster, Hsp90 is expressed as an $83 \mathrm{kDa}$ protein (Sollars et al., 2003), suggesting that the protein species observed here could well be a constitutively produced heat shock protein. However, Hagner-Holler et al. (2004) show that arthropod haemocyanins (also generally in the $70-90 \mathrm{kDa}$ size range) are expected to be common in lower arthropods, so the bands in this size range in the I. klovstadi homogenates could represent several, different, constitutively produced proteins. The insect antifreeze proteins that have been described are in the region of 9-13 kDa (Duman, 2001) and are therefore smaller than would have been detected using our methods. Clearly a proteomics approach, including investigation of post-translational changes, could be particularly interesting in interpreting stress responses in this and other Antarctic Collembola.

\subsection{Physiological drivers of range limitation on small and large scales?}

Antarctic terrestrial arthropods are often studied to elucidate their 'heroic' adaptations to extreme conditions
(Edwards, 1986; Sømme and Block, 1991; Sømme, 1995). Here we use microclimate data to show that environmental tolerances are indeed relevant in the summer, but with the caveat that the adaptations we describe are likely inadequate for survival of winter temperatures. An automatic weather station positioned on the algal flats recorded a minimum air temperature in the 2002 winter of $-40{ }^{\circ} \mathrm{C}$, and a minimum soil temperature (buffered by snow cover) of $-34.6^{\circ} \mathrm{C}$. In 2003 , the recorded winter minimum was $-36^{\circ} \mathrm{C}$ for air, with a soil minimum of $-34.7^{\circ} \mathrm{C}$ (Ian Hawes, pers. comm.). Pryor (1962) spent a winter investigating microclimates at a site within $20 \mathrm{~m}$ of the location of our I. klovstadi dataloggers, and showed that winter-acclimatised I. klovstadi are capable of surviving experimental temperatures below $-50^{\circ} \mathrm{C}$, suggesting that there must be substantial seasonal changes to the physiology of this species. Although winter sampling is unlikely, Cape Hallett is not so inaccessible to preclude possible future early spring or late autumn investigations that might shed light on these phenomena.

Winter conditions at Cape Hallett do not appear to be significantly less severe than those at Cape Bird, some $600 \mathrm{~km}$ further south (Janetschek, 1967; Sinclair and Sjursen, 2001a; Gordon, 2003), and while the growing season is shorter further south, there is no overt climatic or physiological reason preventing North Victoria Land Collembola from surviving in more southerly habitats. Although interactions between water and temperature seem likely to restrict the distribution of $C$. cisantarcticus at Cape Hallett (cf. Hayward et al.'s (2004) observations of $C$. antarcticus), its presence at the ridge site requires further investigation. By contrast, I. klovstadi and F. grisea are able to tolerate relatively severe environmental stresses and are accordingly found further south in North Victoria Land (Frati et al., 1997). The North Victoria Land coastline is characterised by large glaciers sometimes extending several kilometres beyond the coast, and these (combined with the associated katabatic winds) are likely effective barriers for southward dispersal of Collembola. Assuming that the absence of I. klovstadi and C. cisantarcticus at more southerly locations is a consequence of lack of dispersal (and not of availability of food resources, competition with resident microarthropods or too short a growing season), human-mediated transfer of arthropod species between locations in Victoria Land during research and logistic activities may be the biggest current risk to terrestrial arthropod communities in the Ross Sea Region.

\subsection{What is (and is not) known about Antarctic collembolan ecophysiology?}

Although there is a wealth of physiological information for arthropods in the primary literature, in reality, most species that are represented in the matrix are there by virtue of a single investigated parameter, and the geographic extent of these studies is restricted, particularly in the 


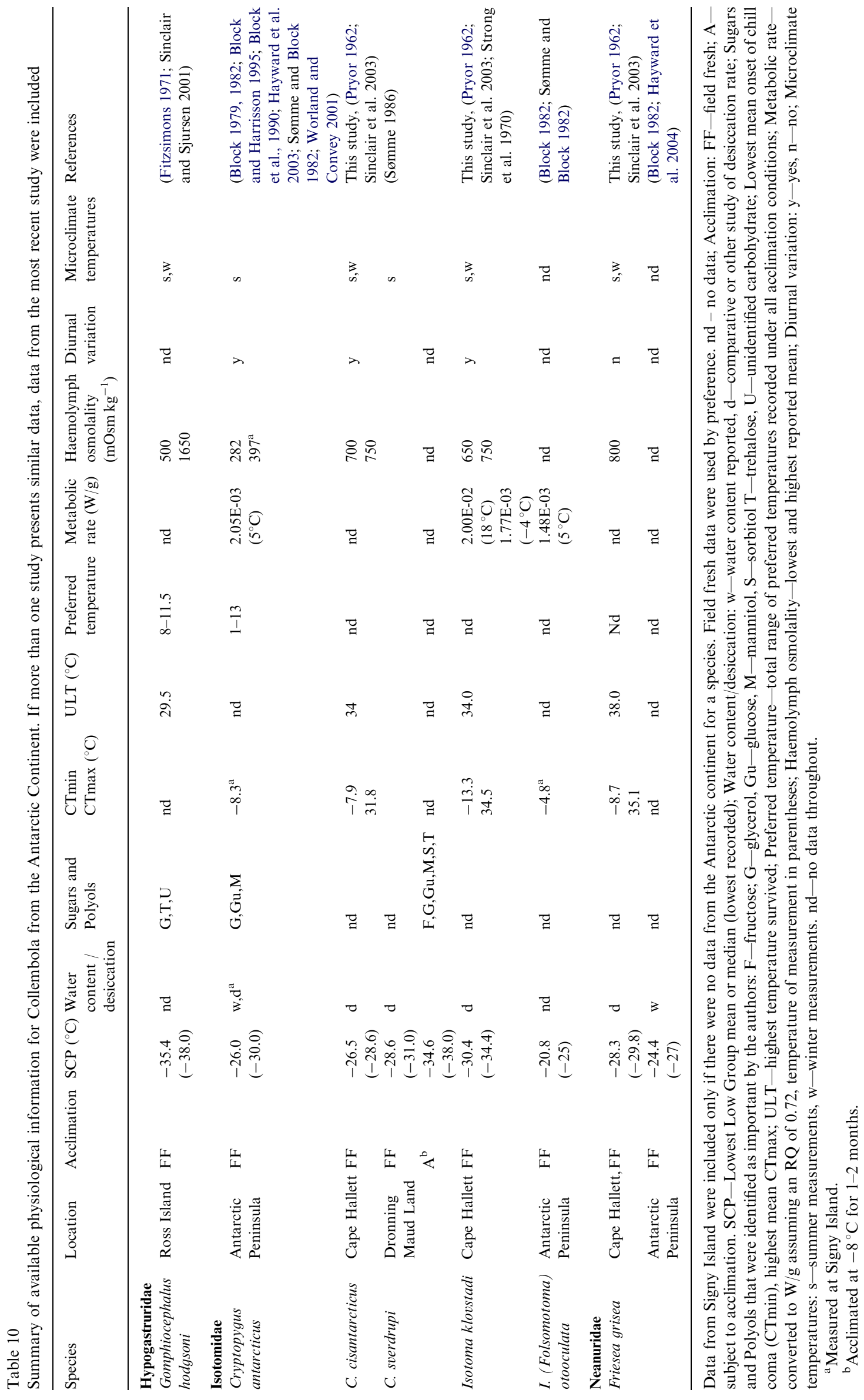


Southern Hemisphere (Chown et al., 2002b; Sinclair et al., 2003a). Within the Southern Hemisphere, Antarctica would seem to be an exception - physiological studies of supercooling in Antarctic Collembola have reached textbook status (Hopkin, 1997; Wharton, 2002; Chown and Nicolson, 2004), and many other aspects of physiology have been reported, including metabolic rates (Strong et al., 1970; Block and Young, 1978) and water balance (Block et al., 1990; Block and Harrisson, 1995; Convey et al., 2003). However, the majority of these studies have been on a single species, $C$. antarcticus (Isotomidae), and many of those were conducted on the comparatively warm and wet Signy Island (Cannon and Block, 1988). Even so, a new strategy of cold hardening - rapid SCPs change - was recently reported for this hitherto well-understood species (Worland and Convey, 2001). With the inclusion of the three species from Cape Hallett, physiological information is now available for seven species of Antarctic Collembola in three families (Table 10), out of approximately 15 described species on the continent. However, only SCPs are available for all seven species, and good winter data are lacking for all species except $C$. antarcticus on Signy Island (Cannon and Block, 1988). Some parameters (e.g. ULT) have been measured only rarely, and metabolic rate has not been measured in any Antarctic Collembola since the 1970s. In addition, we note that there is substantially less physiological information available for the (more diverse) terrestrial Antarctic mite fauna. Given differential rates of climate change across the continent, and the requirement for signatory nations of the Madrid Protocol for Environmental Protection to the Antarctic Treaty (see www.cep.aq) to monitor and conserve the Antarctic biota, we find the present situation extraordinary. We hope that the forthcoming International Polar year (2007) will present an opportunity to improve basic knowledge of and mechanisms underlying the distribution and abundance of springtails across Antarctica. This information will certainly be required before we might pretend to disentangle the effects of natural and anthropogenic change on this important component of the Antarctic biota.

\section{Acknowledgements}

Thanks to Ian Hawes for providing access to AWS data, and Mhairi McFarlane and two anonymous reviewers for comments on an earlier draft of the manuscript. We are grateful to Antarctica New Zealand, the Italian National Antarctic Programme, Helicopters New Zealand, Quark Expeditions and the crew of the icebreaker Kapitan Khlebnikov for logistic support; the Department of Environmental Affairs and Tourism (South Africa), the New Zealand Foundation for Research, Science and Technology and the University of Stellenbosch for funding; First Ascent for protective clothing; members of the Botany and Zoology Department, University of Stellenbosch and Botany Department, University of Otago for technical support; and the members of the Chaperone
Research Laboratory, Department of Biochemistry, Microbiology \& Biotechnology, Rhodes University, for technical assistance with the protein analyses. The FreezeWilly was built by Willy van Rooyen of Central Electronic Services at the University of Stellenbosch, and the Nanoliter osmometer is on loan from Prof. Sue Nicolson, University of Pretoria. This is a contribution to the SCAR EBA programme and the Latitudinal Gradient Project (www.lgp.aq).

\section{References}

Bale, J.S., 1987. Insect cold hardiness: freezing and supercooling - an ecophysiological perspective. Journal of Insect Physiology 33, 899-908.

Bayley, M., Holmstrup, M., 1999. Water vapor absorption in arthropods by accumulation of myoinositol and glucose. Science 285, 1909-1911.

Bayley, M., Petersen, S.O., Knigge, T., Kohler, H.R., Holmstrup, M., 2001. Drought acclimation confers cold tolerance in the soil collembolan Folsomia candida. Journal of Insect Physiology 47, 1197-1204.

Block, W., 1979. Oxygen consumption of the Antarctic springtail Parisotoma otooculata (Willem) (Isotomidae). Revue d'Ecologie et de Biologie du Sol 16, 227-233.

Block, W., 1982. Supercooling points of insects and mites on the Antarctic Peninsula. Ecological Entomology 7, 1-8.

Block, W., 1985. Cold Resistance of two continental Antarctic microarthropods. Cryo-Letters 6, 391.

Block, W., 1994. Terrestrial ecosystems: Antarctica. Polar Biology 14, 293-300.

Block, W., Duman, J.G., 1989. Presence of thermal hysteresis producing antifreeze proteins in the Antarctic mite, Alaskozetes antarcticus. Journal of Experimental Zoology 250, 229-231.

Block, W., Harrisson, P.M., 1995. Collembolan water relations and environmental change in the maritime Antarctic. Global Change Biology 1, 347-359.

Block, W., Young, S.R., 1978. Metabolic adaptations of Antarctic terrestrial microarthropods. Comparative Biochemistry and Physiology 61A, 363-368.

Block, W., Young, S.R., 1979. Measurement of supercooling in small arthropods and water droplets. Cryo-Letters 1, 85-91.

Block, W., Harrisson, P.M., Vannier, G., 1990. A comparative study of patterns of water loss from two antarctic springtails (Insecta, Collembola). Journal of Insect Physiology 36, 181-187.

Cannon, R.J.C., Block, W., 1988. Cold tolerance of microarthropods. Biological Reviews 63, 23-77.

Cannon, R.J.C., Block, W., Collett, G.D., 1985. Loss of supercooling ability in Cryptopygus antarcticus (Collembola: Isotomidae) associated with water uptake. Cryo-Letters 6, 73-80.

Chown, S.L., Nicolson, S.W., 2004. Insect Physiological Ecology. Mechanisms and Patterns. Oxford University Press, Oxford.

Chown, S.L., Addo-Bediako, A., Gaston, K.J., 2002a. Physiological variation in insects: large-scale patterns and their implications. Comparative Biochemistry and Physiology B 131B, 587-602.

Chown, S.L., Addo-Bediako, A., Gaston, K.J., 2002b. Physiological variation in insects: large-scale patterns and their implications. Comparative Biochemistry and Physiology B - Biochemistry \& Molecular Biology 131, 587-602.

Convey, P., 2001. Terrestrial ecosystem responses to climate changes in the Antarctic. In: Walther, G.R., Burga, C.A., Edwards, P.J. (Eds.), Fingerprints of Climate Change. Plenum, New York.

Convey, P., Worland, M.R., 2000. Refining the risk of freezing mortality for Antarctic terrestrial microarthropods. CryoLetters 21, 333-338.

Convey, P., Pugh, P.J.A., Jackson, C., Murray, A.W., Ruhland, C.T., Xiong, F.S., Day, T.A., 2002. Response of antarctic terrestrial microarthropods to long-term climate manipulations. Ecology 83, 3130-3140. 
Convey, P., Block, W., Peat, H.J., 2003. Soil arthropods as indicators of water stress in Antarctic terrestrial habitats? Global Change Biology 9, 1718-1730.

Csermely, P., Schnaider, T., Söti, C., Prohászka, Z., Nardai, G., 1998. The 90-kDa molecular chaperone family: structure, function, and clinical applications. A comprehensive review. Pharmacology \& Therapeutics 79, 129-168.

Danks, H.V., 1991. Winter habitats and ecological adaptations for winter survival. In: Lee, Jr, R.E., Denlinger, D.L. (Eds.), Insects at Low Temperature. Chapman \& Hall, New York, pp. 231-259.

Davey, M.C., Pickup, J., Block, W., 1992. Temperature variation and its biological significance in fellfield habitats on a maritime Antarctic island. Antarctic Science 4, 383-388.

Doran, P.T., Priscu, J.C., Lyons, W.B., Walsh, J.E., Fountain, A.G., McKnight, D.M., Moorhead, D.L., Virginia, R.A., Wall, D.H., Clow, G.D., Fritsen, C.H., McKay, C.P., Parsons, A.N., 2002. Antarctic climate cooling and terrestrial ecosystem response. Nature 415, $517-520$.

Duman, J.G., 2001. Antifreeze and ice nucleator proteins in terrestrial arthropods. Annual Review of Physiology 63, 327-357.

Edwards, J.S., 1986. How small ectotherms thrive in the cold without really trying. Cryo-Letters 6, 388-390.

Ewing, H.E., 1922. Notes on the occurrence and distribution of antarctic land arthropods (springtails and mites: Collembola and Acarina). Entomological News 33, 76-79.

Fitzsimons, J.M., 1971. Temperature and three species of Antarctic arthropods. Pacific Insects Monographs 25, 127-135.

Folk, D.G., Han, C., Bradley, T.J., 2001. Water acquisition and partitioning in Drosophila melanogaster: effects of selection for desiccation-resistance. Journal of Experimental Biology 204, 3323-3331.

Frati, F., Fanciulli, P.P., Carapelli, A., Dallai, R., 1997. The Collembola of northern Victoria Land (Antarctica): distribution and ecological remarks. Pedobiologia 41, 50-55.

Friedmann, E.I., McKay, C.P., Nienow, J.A., 1987. The Cryptoendolithic microbial environment in the Ross Desert of Antarctica: SatelliteTransmitted continuous nanoclimate data, 1984 to 1986. Polar Biology 7, 273-287.

García, L.V., 2004. Escaping the Bonferroni iron claw in ecological studies. Oikos 105, 657-663.

Gordon, S., 2003. Site Description \& Literature Review of Cape Hallett \& Surrounding Areas. Antarctica New Zealand, Christchurch.

Gressitt, J.L., ed. 1967. Entomology of Antarctica, vol. 10. American Geophysical Union, Washington, DC.

Hagner-Holler, S., Schoen, A., Erker, W., Marden, J.H., Rupprecht, R., Decker, H., Burmester, T., 2004. A respiratory hemocyanin from an insect. Proceedings of the National Academy of Sciences of the United States of America 101, 871-874.

Hanc, Z., Nedved, O., 1999. Chill injury at alternating temperatures in Orchesella cincta (Collembola: Entomobryidae) and Pyrrhochoris apterus (Heteroptera: Pyrrhocoridae). European Journal of Entomology $96,165-168$.

Harrington, H.J., Wood, B.L., McKellar, I.C., Lensen, G.J., 1967. Topography and geology of the Cape Hallett district. Victoria Land, Antarctica New Zealand Geological Survey Bulletin 80, Wellington.

Hayward, S.A.L., Worland, M.R., Convey, P., Bale, J.S., 2003. Temperature preferences of the mite, Alaskozetes antarcticus, and the collembolan, Cryptopygus antarcticus from the maritime Antarctic. Physiological Entomology 28, 114-121.

Hayward, S.A.L., Worland, M.R., Convey, P., Bale, J.S., 2004. Habitat moisture availability and the local distribution of the Antarctic Collembola Cryptopygus antarcticus and Friesea grisea. Soil Biology \& Biochemistry 36, 927-934.

Hertzberg, K., Leinaas, H.P., 1998. Drought stress as a mortality factor in two pairs of sympatric species of Collembola at Spitsbergen, Svalbard. Polar Biology 19, 302-306.

Hodkinson, I.D., Coulson, S.J., Webb, N.R., Block, W., 1996. Can high Arctic soil microarthropods survive elevated summer temperatures? Functional Ecology 10, 314-321.
Holmstrup, M., Sjursen, H., Ravn, H., Bayley, M., 2001. Dehydration tolerance and water vapour absorption in two species of soil-dwelling Collembola by accumulation of sugars and polyols. Functional Ecology 15, 647-653.

Holt, R.D., Lawton, J.H., Gaston, K.J., Blackburn, T.M., 1997. On the relationship between range size and local abundance: back to basics. Oikos 78, 183-190.

Hopkin, S.P., 1997. Biology of the Springtails (Insecta: Collembola). Oxford University Press, Oxford.

Hosler, J.S., Burns, J.E., Esch, H.E., 2000. Flight muscle resting potential and species-specific differences in chill-coma. Journal of Insect Physiology 46, 621-627.

IPCC, 2001. Climate Change 2001: The Scientific Basis. Technical Summary IPCC, Geneva.

Janetschek, H., 1963. On the terrestrial fauna of the Ross-Sea area, Antarctica. Pacific Insects 5, 305-311.

Janetschek, H., 1967. Arthropod ecology of South Victoria Land. In: Gressitt, J.L. (Ed.), Entomology of Antarctica. American Geophysical Union, Washington, DC, pp. 205-293.

Kennedy, A.D., 1993. Water as a limiting factor in the Antarctic terrestrial environment: a biogeographical synthesis. Arctic and Alpine Research $25,308-315$.

Kingsolver, J.G., 1989. Weather and the population dynamics of insectsintegrating physiological and population ecology. Physiological Zoology 62, 314-334.

Kingsolver, J.G., Huey, R.B., 1998. Evolutionary analyses of morphological and physiological plasticity in thermally variable environments. American Zoologist 38, 545-560.

Klok, C.J., Chown, S.L., 2003. Resistance to temperature extremes in subAntarctic weevils: interspecific variation, population differentiation and acclimation. Biological Journal of the Linnean Society 78, 401-414.

Kohshima, S., 1984. A novel cold-tolerant insect found in a Himalayan glacier. Nature 310, 225-227.

Laemmli, U.K., 1970. Cleavage of structural proteins during the assembly of the head of bacteriophage T4. Nature 227, 680-685.

Lutterschmidt, W.I., Hutchison, V.H., 1997. The critical thermal maximum: data to support the onset of spasms as the definitive end point. Canadian Journal of Zoology 75, 1553-1560.

Marshall, D.J., Newton, I.P., Crafford, J.E., 1995. Habitat temperature and potential locomotor activity of the continental Antarctic mite, Maudheimia petronia Wallwork (Acari: Oribatei). Polar Biology 15, 41-46.

Marshall, D.J., Pugh, P.J.A., 1996. Origin of the inland Acari of continental Antarctica, with particular reference to Dronning Maud Land. Zoological Journal of the Linnean Society 118, $101-118$.

Meier, P., Zettel, J., 1997. Cold hardiness in Entomobrya nivalis (Collembola, Entomobryidae): annual cycle of polyols and antifreeze proteins, and antifreeze triggering by temperature and photoperiod. Journal of Comparative Physiology B 167, 297-304.

Nedved, O., 1998. Modelling the relationship between cold injury and accumulated degree days in terrestrial arthropods. Cryo-Letters 19, 267-274.

Nunamaker, R.A., 1993. Rapid Cold-Hardening in Culicoides variipennis sonorensis (Diptera, Ceratopogonidae). Journal of Medical Entomology 30, 913-917.

Parmesan, C., Yohe, G., 2003. A globally coherent fingerprint of climate change impacts across natural systems. Nature 421, 37-42.

Peck, L.S., 2002. Ecophysiology of Antarctic marine ectotherms: limits to life. Polar Biology 25, 31-40.

Peck, L.S., Webb, K.E., Bailey, D.M., 2004. Extreme sensitivity of biological function to temperature in Antarctic marine species. Functional Ecology 18, 625-630.

Precht, H., 1958. Concepts of the temperature adaptation of unchanging reaction systems of cold-blooded animals. In: Prosser, C.L. (Ed.), Physiological Adaptation. American Academy for the Advancement of Science, Washington. 
Pryor, M.E., 1962. Some environmental features of Hallett Station, Antarctica, with special reference to soil arthropods. Pacific Insects 4, 681-728.

Quinn, G.P., Keogh, M.J., 2002. Experimental Design and Data Analysis for Biologists. Cambridge University Press, Cambridge.

Rudolph, E.D., 1963. Vegetation of Hallett Station, Victoria Land, Antarctica. Ecology 44, 585-586.

Sinclair, B.J., 2001a. Biologically relevant environmental data: macros to make the most of microclimate recordings. Cryo-Letters 22, 125-134.

Sinclair, B.J., 2001b. Field ecology of freeze tolerance: interannual variation in cooling rates, freeze-thaw and thermal stress in the microhabitat of the alpine cockroach Celatoblatta quinquemaculata. Oikos 93, 286-293.

Sinclair, B.J., Sjursen, H., 2001a. Cold tolerance of the Antarctic springtail Gomphiocephalus hodgsoni (Collembola, Hypogastruridae). Antarctic Science 13, 271-279.

Sinclair, B.J., Sjursen, H., 2001b. Terrestrial invertebrate abundance across a habitat transect in Keble Valley, Ross Island, Antarctica. Pedobiologia 45, 134-145.

Sinclair, B.J., Chown, S.L., 2002. Haemolymph osmolality and thermal hysteresis activity in 17 species of arthropods from sub-Antarctic Marion Island. Polar Biology 25, 928-933.

Sinclair, B.J., Lord, J.M., Thompson, C.M., 2001. Microhabitat selection and seasonality of alpine invertebrates. Pedobiologia 45, 107-120.

Sinclair, B.J., Addo-Bediako, A., Chown, S.L., 2003a. Climatic variability and the evolution of insect freeze tolerance. Biological Reviews 78, 181-195.

Sinclair, B.J., Klok, C.J., Scott, M.B., Terblanche, J.S., Chown, S.L., 2003b. Diurnal variation in supercooling points of three species of Collembola from Cape Hallett, Antarctica. Journal of Insect Physiology 49, 1049-1061.

Sinclair, B.J., Vernon, P., Klok, C.J., Chown, S.L., 2003c. Insects at low temperatures: an ecological perspective. Trends in Ecology \& Evolution 18, 257-262.

Sinclair, B.J., Klok, C.J., Chown, S.L., 2004. Metabolism of the subAntarctic caterpillar Pringleophaga marioni during cooling, freezing and thawing. Journal of Experimental Biology 207, 1287-1294.

Sjursen, H., Sømme, L., 2000. Seasonal changes in tolerance to cold and desiccation in Phauloppia sp. (Acari, Oribatida) from Finse, Norway. Journal of Insect Physiology 46, 1387-1396.

Sollars, V., Lu, X.Y., Xiao, L., Wang, X.Y., Garfinkel, M.D., Ruden, D.M., 2003. Evidence for an epigenetic mechanism by which Hsp90 acts as a capacitor for morphological evolution. Nature Genetics 33, $70-74$.

Sømme, L., 1986. Ecology of Cryptopygus sverdrupi (Insecta: Collembola) from Dronning Maud Land, Antarctica. Polar Biology 6, 179-184.

Sømme, L., 1995. Invertebrates in Hot and Cold Arid Environments. Springer, Berlin.
Sømme, L., 1996. The effect of prolonged exposures at low temperatures in insects. Cryo-Letters 17, 341-346.

Sømme, L., Block, W., 1982. Cold hardiness of Collembola at Signy Island, maritime Antarctic. Oikos 38, 168-176.

Sømme, L., Block, W., 1991. In: Lee, R.E., Denlinger, D.L. (Eds.), Adaptations to alpine and polar environments in insects and other terrestrial arthropods. Chapman \& Hall, New York, pp. 318-359.

Staempfli, C., Becker-van Slooten, B., Tarradellas, J., 2002. Hsp70 instability and induction by a pesticide in Folsomia candida. Biomarkers 7, 68-79.

Strong, F.E., Dunkle, R.L., Dunn, R.L., 1970. Low-temperature physiology of Antarctic arthropods. Antarctic Journal of the United States 5, 123.

Tillbrook, P.J., 1977. Arthropod ecology of South Victoria Land. In: Llano, G.R. (Ed.), Antarctic Terrestrial Biology. American Geophysical Union, Washington, DC, pp. 935-946.

Towbin, H., Staehlin, T., Gordon, J., 1979. Electrophoretic transfer of proteins from polyacrylamide gels to nitrocellulose sheets: procedure and some applications. Proceedings of the National Academy of Sciences of the United States of America 76, 4350-4354.

Walther, G.R., Post, E., Convey, P., Menzel, A., Parmesan, C., Beebee, T.J.C., Fromentin, J.M., Hoegh-Guldberg, O., Bairlein, F., 2002. Ecological responses to recent climate change. Nature 416, 389-395.

Wharton, D.A., 2002. Life at the Limits: Organisms in extreme environments. Cambridge University Press, Cambridge.

Wise, K.A.J., 1967. Collembola (Springtails). In: Gressitt, J.L. (Ed.), Entomology of Antarctica. American Geophysical Union, Washington, DC, pp. 123-148.

Wise, K.A.J., Gressitt, J.L., 1965. Far southern animals and plants. Nature, London 207, 101-102.

Wise, K.A.J., Shoup, J., 1967. Distribution of Collembola at Cape Hallett. In: Gressitt, J.L. (Ed.), Entomology of Antarctica. American Geophysical Union, Washington, DC, pp. 325-330.

Worland, M.R., 2005. Factors that influence the supercooling point of the sub-Antarctic springtail Tullbergia antarctica. Journal of Insect Physiology 51, 881-894.

Worland, M.R., Convey, P., 2001. Rapid cold hardening in Antarctic microarthropods. Functional Ecology 15, 515-524.

Worland, M.R., Block, W., Rothery, P., 1992. Survival of sub-zero temperatures by two South Georgian beetles (Coleoptera, Perimylopidae). Polar Biology 11, 607-613.

Zachariassen, K.E., Husby, J.A., 1982. Antifreeze effect of thermal hysteresis agents protects highly supercooled insects. Nature 298, $865-867$.

Zachariassen, K.E., Kristiansen, E., 2000. Ice nucleation and antinucleation in nature. Cryobiology 41, 257-279.

Zettel, J., 1984. Cold hardiness strategies and thermal hysteresis in Collembola. Revue d'Écologie et de Biologie du Sol 21, 189-203. 